Florida International University FIU Digital Commons

FIU Electronic Theses and Dissertations

University Graduate School

$7-2-1998$

\title{
The herpetofauna of Iwokrama reserve: a comparison of sampling methods
}

Megan Huilan Chen

Florida International University

DOI: $10.25148 /$ etd.FI14060170

Follow this and additional works at: https://digitalcommons.fiu.edu/etd

Part of the Biology Commons

\section{Recommended Citation}

Chen, Megan Huilan, "The herpetofauna of Iwokrama reserve: a comparison of sampling methods" (1998). FIU Electronic Theses and Dissertations. 2138.

https://digitalcommons.fiu.edu/etd/2138

This work is brought to you for free and open access by the University Graduate School at FIU Digital Commons. It has been accepted for inclusion in FIU Electronic Theses and Dissertations by an authorized administrator of FIU Digital Commons. For more information, please contact dcc@fiu.edu. 
Miami, Florida

THE HERPETOFAUNA OF IWOKRAMA RESERVE:

A COMPARISON OF SAMPLING METHODS

A thesis submitted in partial satisfaction of the

requirements for the degree of

MASTER OF SCIENCE

IN

BIOLOGY

by

Megan Huilan Chen 
To: Dean Arthur W. Herriott

College of Arts and Sciences

This thesis, written by Megan $\mathrm{H}$. Chen, and entitled THE

HERPETOFAUNA OF IWOKRAMA RESERVE: A COMPARISON OF SAMPLING METHODS, having been approved in respect to style and intellectual content, is referred to you for judgment.

We have read this thesis and recommend that it be approved.

$$
\begin{aligned}
& \text { Dr. Joel T. Heinen } \\
& \hline \text { Dr. Joel C. Trexler } \\
& \text { Dr. Maureen A. Donnelly, Major Professor }
\end{aligned}
$$

Date of Defense: July 2, 1998

The thesis of Megan H. Chen is approved.

Dean Arthur W. Herriott College of Arts and Sciences

Dr. Richard L. Campbell

Dean of Graduate Studies

Florida International University, 1998 
I dedicate this thesis to my family and Eric for all their support. 


\section{ACKNOWLEDGMENTS}

This research was funded by GEF/UNDP Assistance to Iwokrama International Rain Forest Programme, Project No: GUY/92/G31 and the Florida International University Provost's office. Identification of the specimens was funded by the American Museum of Natural History collection studies, the Division of Amphibians and Reptiles of the Smithsonian Institute, and the Biological Resources Division of USGS. I would like to thank Florida International University's Tropical Biology Program for my summer fellowship and providing a travel award to the American Museum of Natural History and the National Museum of Natural History. I thank BRD of USGS at the National Museum, the curators of AMNH and NMNH, Roy W. McDiarmid, and Darrel Frost for their help. I would also like to thank my committee, Dr. Maureen A. Donnelly, Dr. Joel T. Heinen, and Dr. Joel C. Trexler for their advice and guidance throughout the study. I am grateful to Graham Watkins, Steve Oberbauer, Matt Baber, Cynthie Watson, Dexter Torres, Ron Allicock, Raul Urgelles, Ralph Saporito for help in the field and lab. Eric Pop, Carlo Calandrellio, Hardin Waddle, and Chris Farrell provided indispensible insights. 
ABSTRACT OF THE THESIS

THE HERPETOFAUNA OF IWOKRAMA RESERVE: A COMPARISON OF METHODS

by

Megan Huilan Chen

Florida International University, 1998

Miami, Florida

Professor Maureen A. Donnelly, Major Professor

Inventory sampling provides information on assemblage structure and baseline species diversity data for future comparisons. This study explored the efficiency and accuracy of inventory sampling methods for an assemblage of lowland tropical amphibians and reptiles. Data were collected from the Iwokrama International Centre for Rain Forest Conservation and Development in Guyana. Four standard methods (day visual encounter survey, night visual encounter survey, leaf litter plots, and opportunistic collecting) were used to examine assemblage structure. I analyzed these data to look for variation in amphibian and reptile species diversity among different parts of the reserve and different methods. Species diversity varied among the different populations sampled in terms 
of species richness. Estimations in species richness also varied among methods. Night visual encounter surveys provided the highest average number of individuals and species caught per person-hour of effort. However, a combination of methods portrayed the most accurate species richness within the reserve. 
I. INTRODUCTION

II. METHODS

Study area

Sampling methods

Analysis

III. RESULTS

Abiotic factors

Sampling time

Differences among the camps

Standardized by the number of individuals

Standardized by the number of person-hours expended

Cluster analysis

Method efficiency

Method biases

IV. DISCUSSION

Abiotic factors

Sampling time

Differences among the camps

Standardized by the number of individuals

Standardized by the number of person-hours expended

Cluster analysis

76

Method efficiency

77

Method biases

V. CONCLUSION 


\section{LIST OF TABLES}

Table 1. Length of the sampling periods and location. 14

Table 2. Elevation and habitat types of the sampling sites. 15

Table 3. Sampling frequency of each method used at all localities. 17

Table 4. Comparison of the linear equations among camps. 36

Table 5. Comparison of the linear equations among methods

standardized by the number of individuals 43

Table 6. Comparison of the linear equations among methods

standardized by the number of person-hours. 52

Table 7. Comparison of the number of individuals caught per person-hour among methods.

Table 8. Comparison of the number of species caught per

person-hour among methods. $\quad 64$

Table 9. Amphibian and reptilian families not collected. 68

Table 10. Number of species collected using the different methods. $\quad 70$ 


\section{LIST OF FIGURES}

Figure 1. Map of Guyana

Figure 2. Map of the Iwokrama International Centre for

Rain Forest Conservaton and Development Reserve.

Figure 3. The relationship between rainfall and the number

of species observed.

Figure 4. The relationship between rainfall and the number

of individuals observed.

Figure 5. The relationship between the Julian day and the

number of species observed

Figure 6. The relationship between the Julian day and the

number of individuals observed

Figure 7. Species accumulation curve using all methods.

Figure 8. Species accumulation curves using all the data

collected for three locations.

Figure 9. Species accumulation curves using all the data

collected for five locations.

Figure 10. Species accumulation regression lines for three

locations sampled.

Figure 11. Species accumulation regression lines for five

locations sampled.

Figure 12. Comparison of the estimated number of species among camps.

Figure 13. Species rank abundance for Muri Scrub, Cowfly

Third, and Three Mile camps.

Figure 14. Species rank abundance for Burro-Burro, Kabocalli

Cutline A-B, and Pakatua camps.

Figure 15. The relationship between $\log \mathrm{N}$ and $\log \mathrm{S}$ for each

method.

Figure 16. Comparison of the estimated number of species

among methods at 16 individuals.

Figure 17. Comparison of the estimated number of species

among methods at 56 individuals.

Figure 18. Species rank abundance for the methods

standardized by the number of individuals.

Figure 19. Species rank abundance for the all methods combined

standardized by the number of individuals. 
Figure 20. The number of person-hours and the number of species compared among methods.

Figure 21. Comparison of the estimated number of species among methods at 56 person-hours

Figure 22. Comparison of the estimated number of species among methods at 136 person-hours

Figure 23. Species rank abundance for all methods combined standardized by the number of person-hours.

Figure 24. Cluster diagram using all data collected

Figure 25. Cluster diagram using day visual encounter survey data 58

Figure 26. Cluster diagram using night visual encounter survey data $\quad 59$

Figure 27. Cluster diagram using opportunistic collecting data $\quad 60$

Figure 28. Cluster diagram using leaf litter plot data 61

Figure 29. Percentage of relative reptilian family richness. 66

Figure 30. Percentage of relative amphibian family richness 67 


\section{$\underline{\text { Introduction }}$}

One of the driving questions in community ecology is to determine what processes control structural differences and similarities among communities (Losos 1994; Hecnar and M'Closkey 1997). Community structure is influenced by three primary descriptors: species richness, species evenness and guild types (Heatwole and Taylor 1987, Worthen 1996). Long-term sampling not only provides information about these three descriptors, but can also gather information on local extinction rates, population trends, and human impacts (Heyer et al. 1994). Tropical forests of the world support diverse assemblages of amphibians and reptiles, but these herpetofaunal assemblages have not been well studied.

Researchers have used a single method to sample amphibians and reptiles (Toft 1980, Lieberman 1986, Inger et al. 1987, Moreira and Lima 1991, Allmon 1994,Vitt and Caldwell 1994,) or a combination of methods (Inger and Colwell 1977, Inger 1980, Friend and Cellier 1990, Duellman 1995, Zimmerman and Simberloff 1996) but few studies have determined how sampling methods compared in their efficiencies. Pearman et al. (1995) compared the efficiencies of four methods and found differences in species richness among methods, but these methods were compared without 
standardizing effort. It is important to understand the relationship between herpetofaunal sampling methods and species diversity so that studies can be compared accurately.

Species diversity is the combination of two components, species richness and species evenness (Baltanau 1992). Species richness (number of species within a community) is the result of a balance between regional (i.e., species formation and geographical dispersal) and local (i.e., predation, competition, adaptation and stochastic variation) processes (Ricklefs 1990). Species evenness compares the abundances of species within a community. Species diversity is important when examining community structure. A non-random pattern of species diversity among multiple communities can suggest potential mechanisms that underlie community structure (Worthen 1996). Data on species diversity patterns also have potential use in conservation by allowing researchers to predict changes in species diversity patterns that occur as a consequence of habitat fragmentation (Worthen 1996). It is important for conservationists and land managers to understand the processes behind species diversity patterns and historical background because the number of endemic species within an area can be related to its size and shape (Williams and Pearson 1997). However, baseline data are 
essential to accurately determine changes in species diversity within a community. The lack of published baseline data on amphibians and reptiles is one crucial problem in conservation biology (Busby and Parmalee 1996).

Many other uses exist for species richness and evenness data.

Conservation potential and ecological value of communities can be determined by looking at abundance patterns within an area (Miller and White 1986) and patterns of endemism (Williams and Pearson 1997). Species-area and species-individual curves can also be developed from species richness and evenness data giving researchers the ability to predict community extinction rates caused by anthropogenic influences and thus make suggestions for species conservation (Condit et al. 1996).

Habitat destruction is the single greatest cause of species loss within communities (McCarthy et al. 1997). Tropical deforestation and land conversion are the root causes of the current global biodiversity crisis, and only extensive forest tracts contain a complete set of a region's indigenous biota (Turner 1996). It is essential to determine which species, communities, and ecosystems have the greatest potential to be destroyed from high species extinction rates, and the increasing levels of humancaused habitat degradation (Nilsson and Grelsson 1995; Gaston 1996). 
Tropical forests are particularly susceptible because they are characterized by high levels of fragility and a high degree of change in species diversity following disturbance (Tokeshi 1993; Nilsson and Grelsson 1995).

Consequently these systems have a high probability of being damaged due to habitat destruction.

Herpetofaunal communities are good indicators of ecosystem deterioration because most amphibians depend on both terrestrial and aquatic habitats. Amphibians can be the largest proportion of vertebrate biomass within a system (Burton and Likens 1975) which makes them potentially good indicators of environmental stress (Blaustein and Wake 1990; Blaustein et al. 1994). In addition, these organisms can be found in a variety of diverse habitats (Hecnar and M'Closkey 1996). According to Steele et al. (1984), a community is less likely than a single species to experience erratic fluctuations, so anthropogenic impacts can be discriminated from natural cycles. Hecnar and M'Closkey (1996) found that there is little difference in amphibian species diversity among years with low turnover rates within and among temperate regions. Herpetofaunal assemblage patterns may be used to examine tropical system fragility in the face of high levels of species loss. 
Amphibians are an essential part of many ecosystems. They not only live in both the aquatic and terrestrial habitats, but they are also important consumers and essential sources of prey within ecosystems (Blaustein and Wake 1990). The possible global decline of this group of organisms has significant implications for various ecosystems and other organisms within these systems (Blaustein and Wake 1990; Blaustein et al. 1994; Donnelly and Crump in press). This phenomenon cannot be fully explained by stochastic events (Blaustein and Wake 1990), and the factors behind this global decline seem to be linked to climatic changes, but are not fully understood (Donnelly and Crump in press). Climatic change is likely to have the largest impact on narrowly endemic Neotropical amphibian species. The loss of these narrowly endemic species would lead to the irreversible transformation of the communities they inhabit if they play "keystone" roles (Donnelly and Crump in press). The worldwide amphibian decline is difficult to study and assess because there is a lack of basic species diversity knowledge (Busby and Parmalee 1996). Although there is not the same decline seen in reptilian species, they are still threatened by extinction from human-caused destruction. Collecting baseline data and completing census studies are essential to addressing this problem, 
determining the nature of the decline, and identifying the driving forces behind these changes (Blaustein et al. 1994; Donnelly and Crump in press).

Previous studies have found that community patterns are influenced by different abiotic and biotic factors. Scott (1976) compared two Neotropical and two Paleotropical sites which differed in total rainfall and length of the dry season and found higher herpetofaunal abundance at the Neotropical sites. He proposed that these differences could be due to differences in leaf litter faunal diversity or differences in the functioning of the total system (Scott 1976). Species abundance also varies among the Neotropical and Paleotropical localities due to changes in climate, vegetation structure, and predation (Inger 1980). The amount of disturbance at a site also affects the abundance, dominance, and representation of rare species (Heinen 1992). Species richness increases with environmental predictability (Inger and Colwell 1977). Differences in diversity among study sites are also influenced by geographic isolation, altitude (Inger et al. 1987), and season (Friend and Cellier 1990; Allmon 1994).

The techniques used in previous studies collect information with variable success. For example using leaf litter plots, Allmon (1994) found only half of the anuran leaf litter species from a site in the central Amazon 
of Brazil, and no animals were found in half of his plots. In addition, very few non-anurans (e.g., caecilians and amphisbaenids) were found in Allmon's plots. One study comparing different sampling methods found that night visual encounter surveys encountered more species than other methods and there were large differences in the number of species collected using different sampling methods (Pearman et al. 1995). To describe community structure, one needs information about the relative efficiencies of trapping when designing a sampling protocol or analyzing data (Williams and Brown 1983; Greenberg et al. 1994; Balkuom et al. 1996). Studies comparing various methods will allow community research to be designed for maximum efficiency and utilization (Scott and Campbell 1982). Knowing the differences among sampling methods and the efficiency of each method can help researchers construct an accurate picture of various systems with the most efficient use of time and personnel.

The present study was part of a vertebrate survey of the Iwokrama Reserve, in central Guyana. This study compared the effectiveness of four sampling methods in a tropical lowland herpetofaunal assemblage. In particular, it tested existing techniques by comparing the efficiency and accuracy of these methods in supplying the most information about the 
herpetofaunal community during the sampling period. I examined differences in species diversity determined by four standard sampling methods by addressing the following questions: (1) What is the relationship between the number of individuals or the number of species and rainfall patterns? (2) Is an asymptote reached in species accumulation curves for the entire sampling period or each locality sampled? (3) How does the assemblage structure (e.g., species richness and species evenness) compare among localities within Iwokrama Reserve? (4)What method (daytime visual encounter survey [VES], nighttime VES, leaf litter plots, or opportunistic collecting) is the most accurate and efficient in obtaining assemblage parameters (e.g., species richness and species abundance)?

Are there biases towards any taxon (e.g., families) by using different methods? (6) Is there overlap among methods or are some species excluded by using certain methods?

\section{Methods}

\section{Study area}

This study was conducted in Guyana (Figure 1), a South American country between $1-9^{\circ} \mathrm{N}$ and $56-62^{\circ} \mathrm{W}$. Guyana encompasses 19.6 million hectares of which $83 \%$ are still covered with forest and woodlands. Guyana 


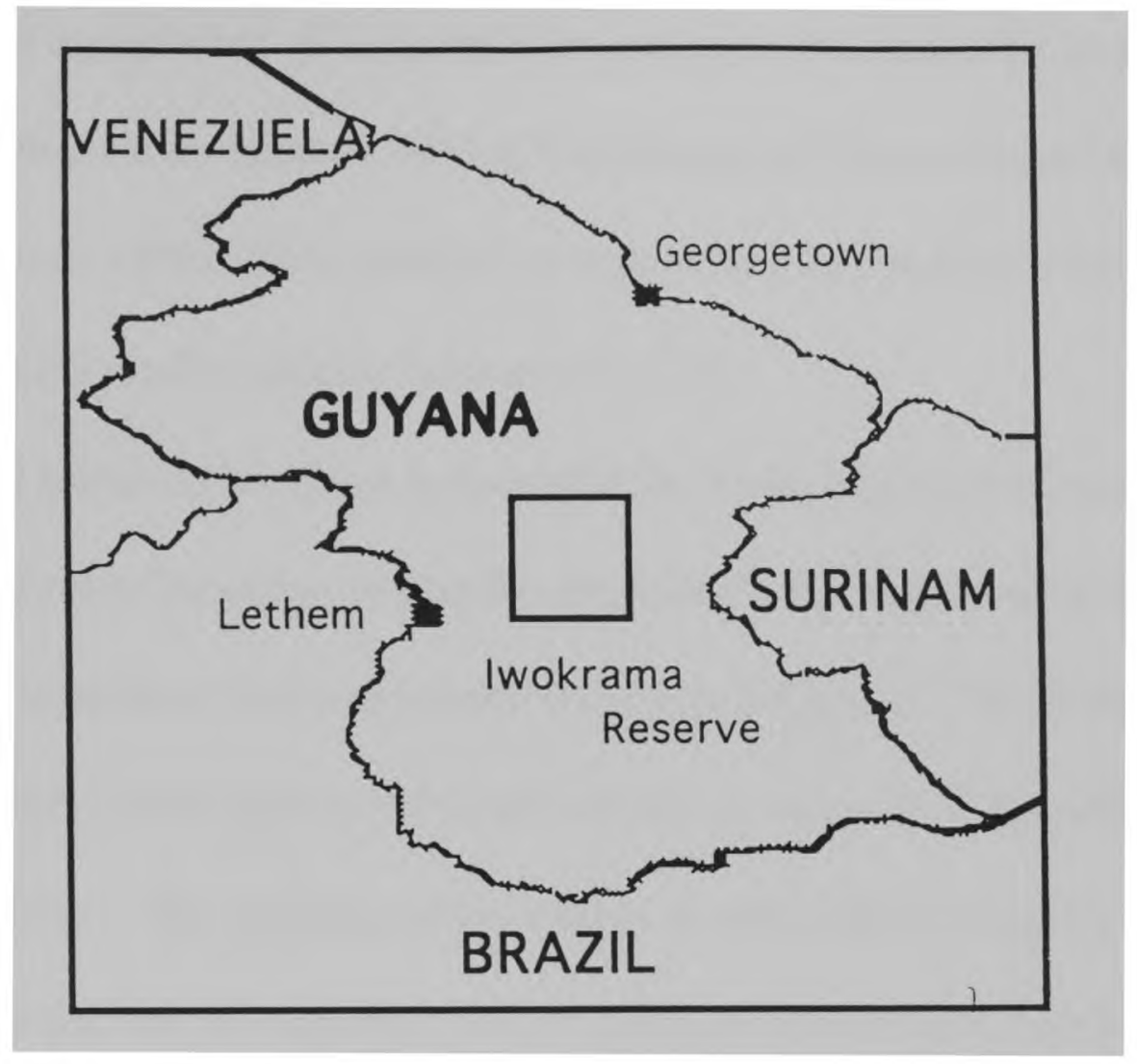

Figure 1. Map of Guyana. Located between $1-9^{\circ} \mathrm{N}$ and $56-62^{\circ} \mathrm{W}$. 
is one of the few tropical countries which has a large proportion of its forest intact and unexploited. The forest is not presently threatened by increasing population pressure because $90 \%$ of the population lives in coastal areas (Anonymous 1996). This country is characterized by a tropical climate with temperatures usually ranging between $24-32^{\circ} \mathrm{C}$.

All sampling localities were within the Iwokrama International Centre for Rain Forest Conservation and Development Reserve (hereafter referred to as the Iwokrama Reserve) in central Guyana (Figure 2). The Iwokrama Reserve was established in 1996 and includes an expanse of 360,000 ha of tropical forest. The majority of the reserve is within the wet marine zone. This zone has two wet seasons, two dry seasons, and annual rainfall is greater than $2000 \mathrm{~mm}$. The main topographic feature within the Reserve is the Iwokrama Mountain Range. This range of mountains is surrounded by plains which are between $60-100 \mathrm{~m}$ above sea level. All localities are considered lowland tropical forest since they are located within these plains or slightly above them (below 152m) (Kerr 1993). This region of Guyana typically has poorly-drained sand, alluvial, and red clay soils.

The lowland forest of Iwokrama Reserve is mixed and no single tree species is dominant (Kerr 1993), but there are three major forest types: 


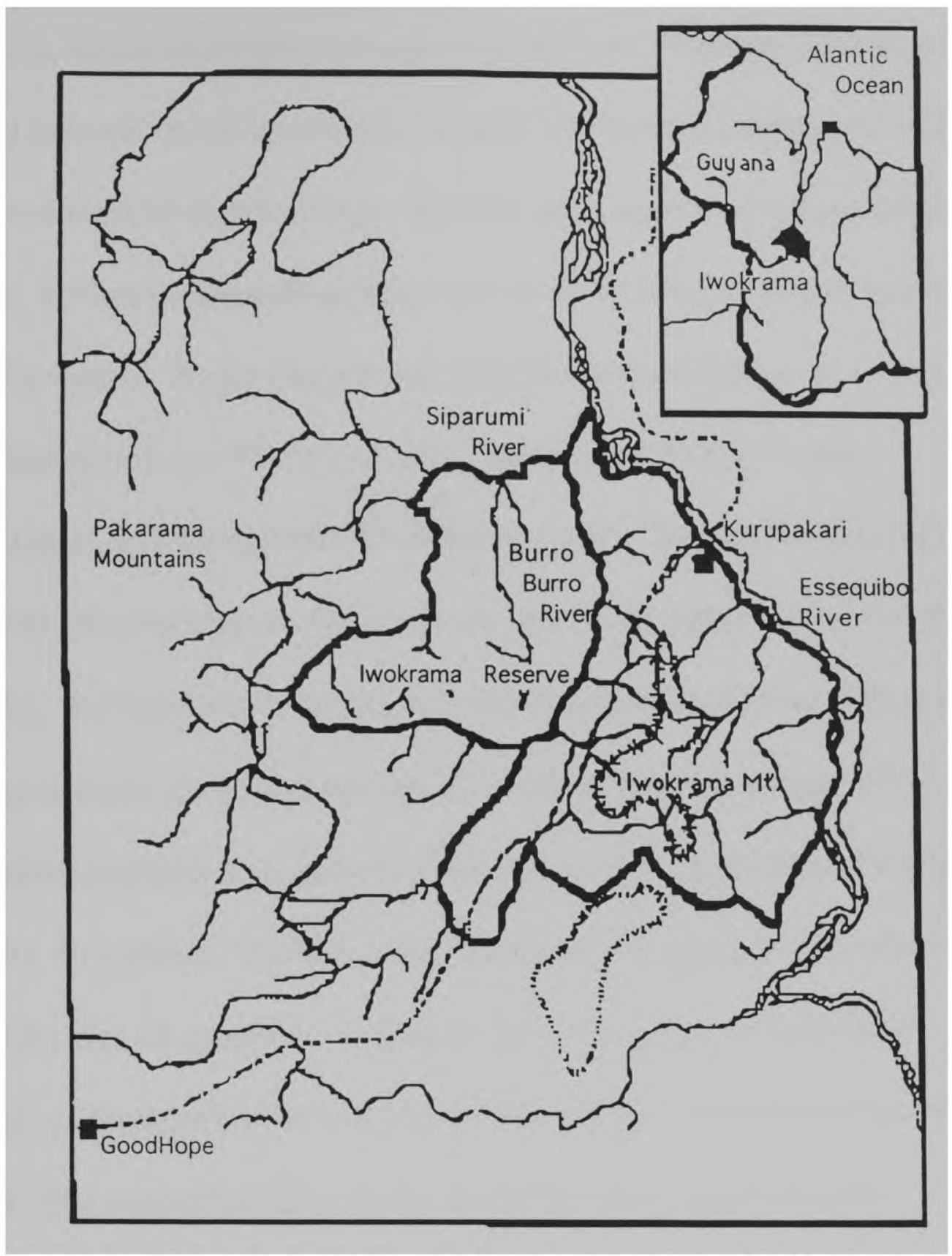

Figure 2. Map of the Iwokrama International Centre for Rain Forest Conservation and Development Reserve. Located at $4^{\circ} \mathrm{N}$ and $58^{\circ} \mathrm{W}$. 
wallaba, mixed heterogeneous, and swamp forest. Wallaba (Eperua falcata) forest is found on white sand soil terraces between the Essequibo River and the Iwokrama Mountain Range. Wallaba has a maximum canopy height of $27 \mathrm{~m}$. Mixed heterogeneous forest occurs on well-drained sands and clays in hilly terrain. This forest has a maximum canopy height of $33 \mathrm{~m}$ and includes greenheart (Ocotea rodiaei), black kakaralli (Eschweilera sagotiana), and warmaratan (Brownea sp.) trees. Swamp forest occurs on alluvial silts and clays at slightly lower elevations typically along rivers and creeks. Swamp forest is composed primarily of mora (Mora excelsa) trees but sometimes has a large number of morabukea (Mora gonggrijpii), kautabali (Licania sp.), and crabwood (Carapa sp.) individuals (Vieria 1980). In addition, savannah scrub and disturbed areas are two other habitats that we sampled which make up smaller areas of Iwokrama Reserve. Savannah scrub is a low uniform small-crowned forest on white sand. The vegetation types in this habitat includes muri (Humiria balsamifera), wallaba (Eperua falcata), and baromalli (Catostemma sp.).

Disturbed habitats (camp and areas around the Georgetown-Lethem road which bisects the reserve) includes a large number of pioneer tree species (e.g., Cecropia angulata) (Hawkes and Wall 1995). 
Sampling was performed at eight different locations within the reserve for 6-11 consecutive days (Table 1). The locations included: Muri scrub camp, Cowfly camp, Third camp, Three mile camp, Burro Burro camp, Kabocalli camp, Cutline A-B camp, and Pakatau camp. Muri scrub, Cowfly, Third, Three mile, and Cutline A-B camps were accessed by land from the Karupakari base camp. Burro Burro, Kabocalli, and Pakatau were located on the three major rivers found in the reserve: Burro Burro, Essequibo, and Siparuni Rivers, respectively (Hawkes and Wall 1995) and were accessed by boat.

These camps varied slightly in terms of habitat type and elevation (Table 2). Muri scrub camp was $41.2 \mathrm{~km}$ southwest from Kurupukari (the Iwokrama Reserve base camp) on the Georgetown-Lethem road. Cowfly camp was $5 \mathrm{~km}$ up the mountain gorge cutline trail from Muri Scrub camp. Third camp was farther up the mountain gorge cutline trail from Cowfly camp into the foothills of the Iwokrama mountain range. Three-mile camp was $4.83 \mathrm{~km}$ from the Kurupukari base camp southwest on the GeorgetownLethem road. Burro Burro camp was on the Burro Burro river, a tributary of the Essequibo river, southwest of Kurupukari base camp. Kabocalli camp was southeast of Kurupukari base camp on the Essequibo river. Cutline A- 
Table 1. Length of the sampling periods and location of sampling site within the Iwokrama Reserve. Dates are given as month/day/year.

\begin{tabular}{lllc}
\hline Camp & $\begin{array}{l}\text { Date } \\
\text { sampled }\end{array}$ & $\begin{array}{l}\text { GPS } \\
\text { position }\end{array}$ & $\begin{array}{c}\text { \# of days } \\
\text { sampling }\end{array}$ \\
\hline Muri Scrub & $5 / 8 / 97-5 / 13 / 97$ & $4^{\circ} 25.2^{\prime} \mathrm{N}, 58^{\circ} 50.96^{\prime} \mathrm{W}$ & 6 \\
Cowfly & $5 / 14 / 97-5 / 20 / 97$ & not obtained & 7 \\
Third & $5 / 21 / 97-5 / 26 / 97$ & not obtained & 6 \\
Three Mile & $5 / 28 / 97-6 / 7 / 97$ & $4^{\circ} 37.98^{\prime} \mathrm{N}, 58^{\circ} 42.87^{\prime} \mathrm{W}$ & 11 \\
Burro-Burro & $6 / 9 / 97-6 / 19 / 97$ & $4^{\circ} 43.86^{\prime} \mathrm{N}, 58^{\circ} 51.04^{\prime} \mathrm{W}$ & 11 \\
Kabocalli & $6 / 24 / 97-7 / 3 / 97$ & $4^{\circ} 17.10^{\prime} \mathrm{N}, 58^{\circ} 30.56^{\prime} \mathrm{W}$ & 9 \\
Cutline A-B & $7 / 3 / 97-7 / 10 / 97$ & $4^{\circ} 35.00^{\prime} \mathrm{N}, 58^{\circ} 44.85^{\prime} \mathrm{W}$ & 8 \\
Pakatau & $7 / 13 / 97-7 / 22 / 97$ & not obtained & 10 \\
\hline
\end{tabular}


Table 2. Elevation and habitat types of the sampling sites within the Iwokrama Reserve.

\begin{tabular}{|c|c|c|c|c|c|c|}
\hline Camp & Elevation (m) & Wallaba & $\begin{array}{l}\text { Mixed } \\
\text { heterogeneous }\end{array}$ & Swamp & $\begin{array}{l}\text { Savannah } \\
\text { scrub }\end{array}$ & $\begin{array}{l}\text { Disturbed } \\
\text { areas }\end{array}$ \\
\hline Muri Scrub & 80 & no & yes & yes & yes & yes \\
\hline Cowfly & 120 & yes & yes & yes & no & yes \\
\hline Third & 224 & no & yes & yes & no & yes \\
\hline Three Mile & 102 & yes & yes & yes & no & yes \\
\hline Burro-Burro & 83 & yes & yes & yes & no & yes \\
\hline Kabocalli & 101 & no & yes & yes & yes & yes \\
\hline Cutline A-B & 70 & yes & yes & yes & yes & yes \\
\hline Pakatau & 85 & yes & yes & yes & no & yes \\
\hline
\end{tabular}


B camp was $1.61 \mathrm{~km}$ from Kurupukari base camp southwest on the

Georgetown-Lethem road. Pakatau camp was on the Siparuni river, a tributary of the Essequibo river, southwest of Kurupukari base camp.

\section{Sampling Methods}

The eight camps were sampled by five to eight people using four different methods: day visual encounter surveys (DVES), night visual encounter surveys (NVES), leaf litter plots, and opportunistic collecting.

The persons within each sampling group rotated so the same persons did not always work together. Rotation of observers also decreases the inter-group observer variability (Henke 1998). The efficiency of the search groups can be assumed to be constant since they were searching for the same items in each sample (Henke 1998). The maximum and minimum temperature and rainfall were collected at the beginning of each day (ca. 0600 hours). All the sampling was completed on trails cut specifically for the survey by local Amerindian people. Trails were haphazardly chosen throughout the forest around camp. Opportunistic collecting and NVES were performed each 24 hour period during the stay at each camp. Leaf litter plots and DVES were completed on alternate days (Table 3). These standardized methods (Heyer et al. 1994) have been used effectively by several works. Collected animals 
Table 3. Sampling frequency of each method used at all localities: opportunistic collecting (OC), leaf litter plots (LLP), night visual encounter survey (NVES), and day visual encounter survey (DVES).

\begin{tabular}{lllll}
\hline Day & DVES & LLP & NVES & OC \\
\hline 1 & yes & no & yes & yes \\
2 & no & yes & yes & yes \\
3 & yes & no & yes & yes \\
4 & no & yes & yes & yes \\
5 & yes & no & yes & yes \\
6 & no & yes & yes & yes
\end{tabular}


were euthanized (using Orajel or pentobarbital) and preserved each morning using $10 \%$ formalin and stored in $70 \%$ ethanol. Liver and muscle tissue were removed during the preserving process and were stored in $95 \%$ ethanol.

Day visual encounter surveys (Crump and Scott 1994) were performed every other day at every camp. The observers walked in one direction through the forest on trails cut by local Amerindians for a monitored time period during the day. These periods varied between one to four hours depending on the trail length, but generally lasted one to two hours. Day visual encounter surveys were done during two periods in the day: morning (between 900-1200 hours) and afternoon (between 1300-1700 hours). The people sampling, general habitat type, trail walked, time per VES, identification, and time each animal was observed or collected were recorded.

Night visual encounter surveys (Crump and Scott 1994) were performed every night at every camp. The samplers walked in one direction through the forest along the same trails used for DVES or rode in a boat along a river after sunset (usually between 1900-2300 hours) for a monitored period of 1-3 hours. The people sampling, general habitat type, 
trail walked, time per VES, identification, and time each animal was observed or collected were recorded.

Leaf litter plots (Jaeger and Inger 1994) were completed every other day at every camp between 1300-1600 hours. The observers haphazardly chose $5 \mathrm{X} 5$ meter and $8 \times 8$ meter square plots in the forest, cleared the perimeter, and searched in the litter from the perimeter to the center of the plot looking for animals. The people sampling, time per plot, habitat, and animals seen or collected were recorded. All the plots had the same general characteristics: continuous canopy cover, greater than $500 \mathrm{~m}$ from the edge of continuous forest, and minimal slope.

Opportunistic collecting (Scott 1994) was done continuously during periods which were not part of a specific sampling method. The date and location the animal was collected were recorded. The samplers collected amphibians and reptiles in and around camp, primarily in disturbed areas and during hunting expeditions.

Pitfall traps (Corn 1994) were only used at the Three Mile camp. It was not possible to duplicate pitfall traps at other camps because of lack of time, personnel, and materials. Pitfall traps were opened along drift fences. These fences were located on the Three Mile Cutline $1.61 \mathrm{~km}$ southwest of 
the Georgetown-Lethem road from Three Mile camp. The pitfall trap sampling consisted of two $50 \mathrm{~m}$ fences perpendicular to the cutline, with eleven 19 liter buckets each sunk level into the ground at $5 \mathrm{~m}$ intervals. The drift fences were made of $1 \mathrm{~m}$ high solid black plastic fencing and held down by sand. The buckets were opened continuously during our stay at that camp and checked at least once a day for animals. The sampler recorded the time checked, line, and animals found during the sampling period.

\section{Analysis}

To complete the analysis among camps and methods, the "best estimate" of herpetofaunal assemblage structure was assumed to be equal to the assemblage based on a combination of all methods used at all sites in the Iwokrama Reserve (DVES, NVES, opportunistic collecting, and leaf litter plots). In other words, all the information collected gives the best description of assemblage composition. This assumption was based on the idea that the most realistic representation can be seen using longer periods of sampling (e.g., species accumulation curves see Miller and White 1986) and the fact that some methods found animals not found by others. 
Sample size dependence of species counts was eliminated by

measuring the number of species in terms of the number of individuals (Heyer et al. 1994) or effort. The relationships between the number of individuals and number of species captured and daily rainfall were examined with regression (TableCurve 1989). The relationships between the number of individuals and the number of species captured and short term temporal patterns also were examined. These data were transformed by $20 \%$ smoothing using the lowess algorithm to include autocorrelation before the best fit model was calculated (TableCurve 1989).

Species accumulation curves were generated for each camp and the entire reserve to look at the effects of the length of sampling time. The different localities or camps within Iwokrama Reserve were compared in terms of species richness and species evenness using a standardized sample size. Regression analysis of species richness standardized for the number of individuals collected and permitted comparison of different localities and estimates of the number of species with $95 \%$ confidence intervals (Table Curve 1989). Species evenness for the different localities sampled was examined using species rank abundance graphs. 
The data were analyzed for differences in assemblage structure among methods. I did not use diversity indices to examine species diversity because species diversity indices cannot be interpreted in a biologically meaningful way, they have no probability basis, and sampling bias can be caused by differences in sample size (Gotelli and Graves 1996). I analyzed the two components of species diversity, species richness and species evenness, independently. Species richness and species evenness estimates were standardized since the area sampled, time expended, and the number of individuals captured were not equal among camps or methods. I standardized these data in two different ways. The number of individuals encountered $(\mathrm{N})$ and the number of person-hours expended were used to examine both the accuracy and the efficiency of the methods, respectively . I estimated the number of person-hours expended by opportunistically collecting to be one person-hour per day for each person in camp. One person-hour per day was a conservative estimate and we probably spent more time collecting opportunistically. The data were pooled from all samples for each method and standardized by taking an equal proportion of these samples from every camp. These data were used to estimate the number of species observed at a certain number of individuals. 
Estimates of species richness were calculated using regression curves and compared among methods because this is usually the most accurate method when using a complete data set (Hayek and Buzas 1997). The assumption of normality was met. Residual plots were examined to assess the homogeneity of the variances. Estimates of the number of species caught and their $95 \%$ confidence intervals were compared among the different methods (Table Curve 1989). The number of individuals used to compare species richness among methods was within the observed range for all methods because it is unsafe to extrapolate from regression equations (Zar 1984). The species estimates of the different methods were also compared to a species estimate using all the data.

The other component of species diversity (evenness) was also examined. Species evenness was illustrated using species rank abundance graphs for the different methods (Magurran 1988). These figures were analyzed to examine patterns of species abundance within the assemblage based on each method.

Cluster analysis arranges cases into groups based on similarities or differences to look at species diversity as a whole. The results from cluster analysis can be used to make statements about the species diversity among a 
number of different sites (Magurran 1988). I used Unweighted Pair-Group Average (UPGMA) cluster analysis with percent disagreement to examine patterns of similarity among sites using a covariance matrix (Statistica 1997). I used presence/absence data (Magurran 1988) based on standardized species data among different methods.

I calculated the number of species and number of individuals caught per person-hour of effort to look at method efficiency. Efficiency is defined as "being productive at the desired results" (i.e., catching animals) (Merriam-Webster 1995). The assumptions of normality and homogeneity of variances were not met, so nonparametric statistical tests were used. The Kruskal-Wallis test, an analysis of variance by ranks, was used to determine if there were differences among methods (Statistica 1997). A nonparametric post hoc Tukey-type multiple comparisons test with unequal sample sizes was used to determine which mean ranks were different among methods (Zar 1984).

I compared the proportion of amphibian and reptile families caught by the different methods to see if any method was biased towards any taxon (e.g., family). In addition, species lists were used to determine the "best" 
combination of methods. The pitfall trapping species list was compared to the other species list determine if any species were unique to pitfall traps.

\section{$\underline{\text { Results }}$}

\section{Abiotic factors}

I examined the relationship between the number of animals observed and rainfall or time (Julian date) for abiotic patterns. I found no relationship between the number of animals observed and the amount of rainfall or Julian days $\left(\mathrm{F}_{3,64}=14.2886, \mathrm{p}=0.01, \mathrm{r}^{2}=0.4011\right)$. There was no relationship between rainfall and the number of species (Figure 3; $F_{1,66}=8.54, p=0.01$, $r^{2}=0.1146$ ) or the number of individuals (Figure 4; $F_{1,66}=5.44, p=0.05$, $\mathrm{r}^{2}=0.0761$ ). I found weak relationships between time (in terms of Julian days) and the number of species (Figure $5 ; F_{4,63}=21.29, \mathrm{p}=0.01, \mathrm{r}^{2}=$ 0.5748 ) or number of individuals (Figure $6 ; F_{4.63}=14.56, p=0.01, r^{2}=$ $0.4804)$.

\section{Sampling time}

The length of the sampling period was examined with species accumulation curves. The species accumulation curve increased rapidly for the first 500 individuals, and slowly increased thereafter for the entire sampling period within the Iwokrama Reserve (Figure 7). I also constructed 


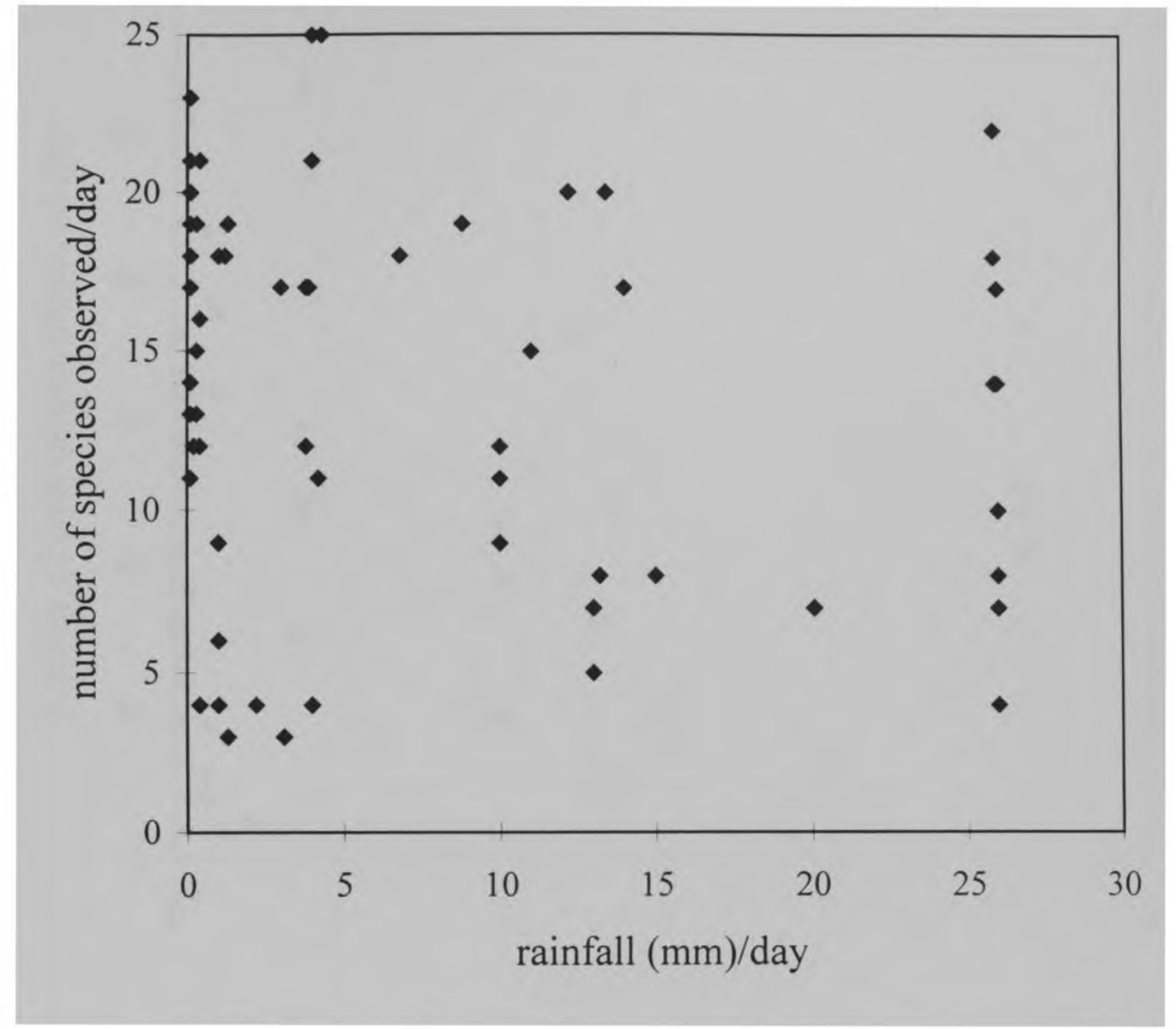

Figure 3. The relationship between rainfall and the number of species observed. 


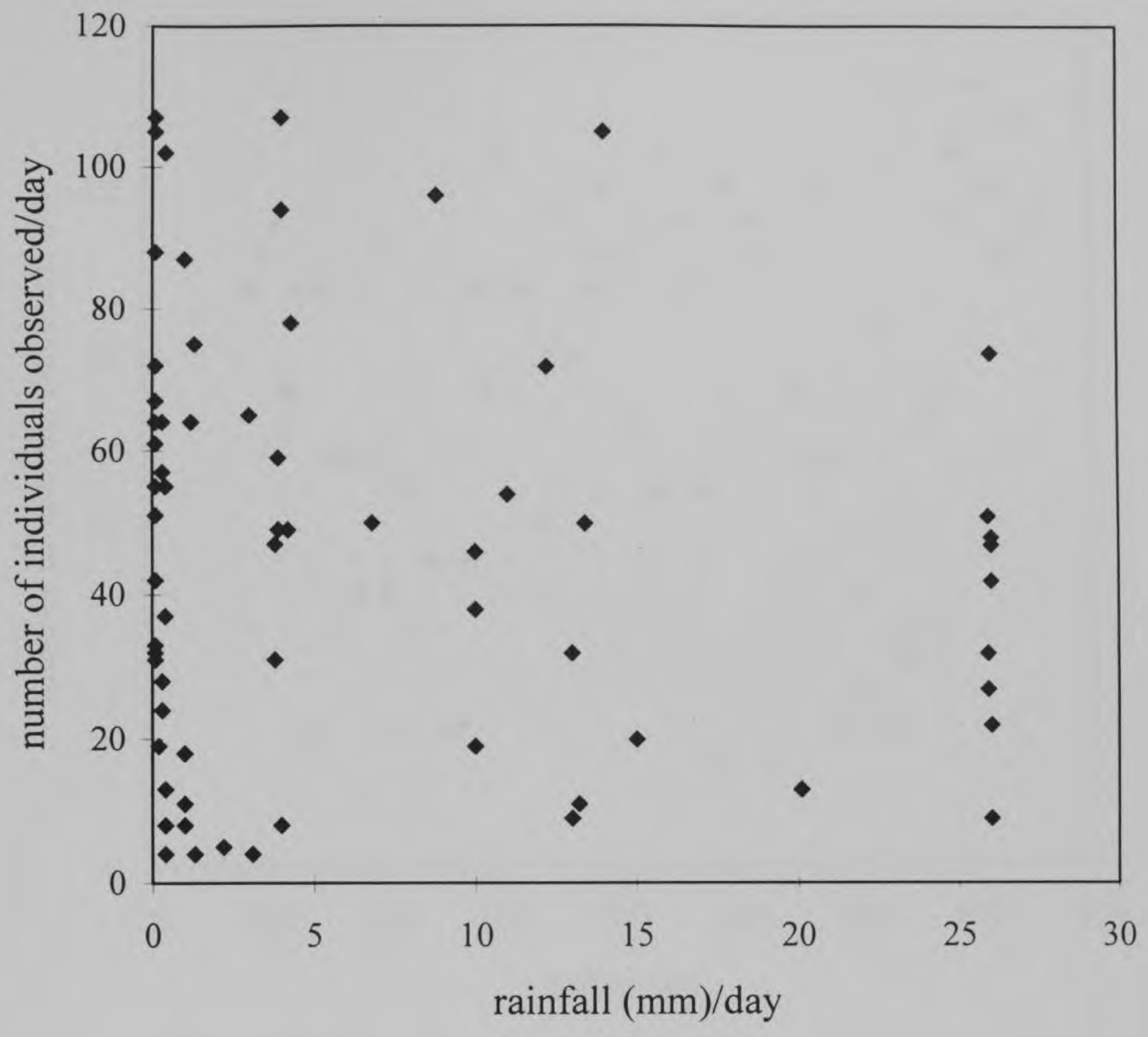

Figure 4. The relationship between rainfall and the number of individuals observed. 


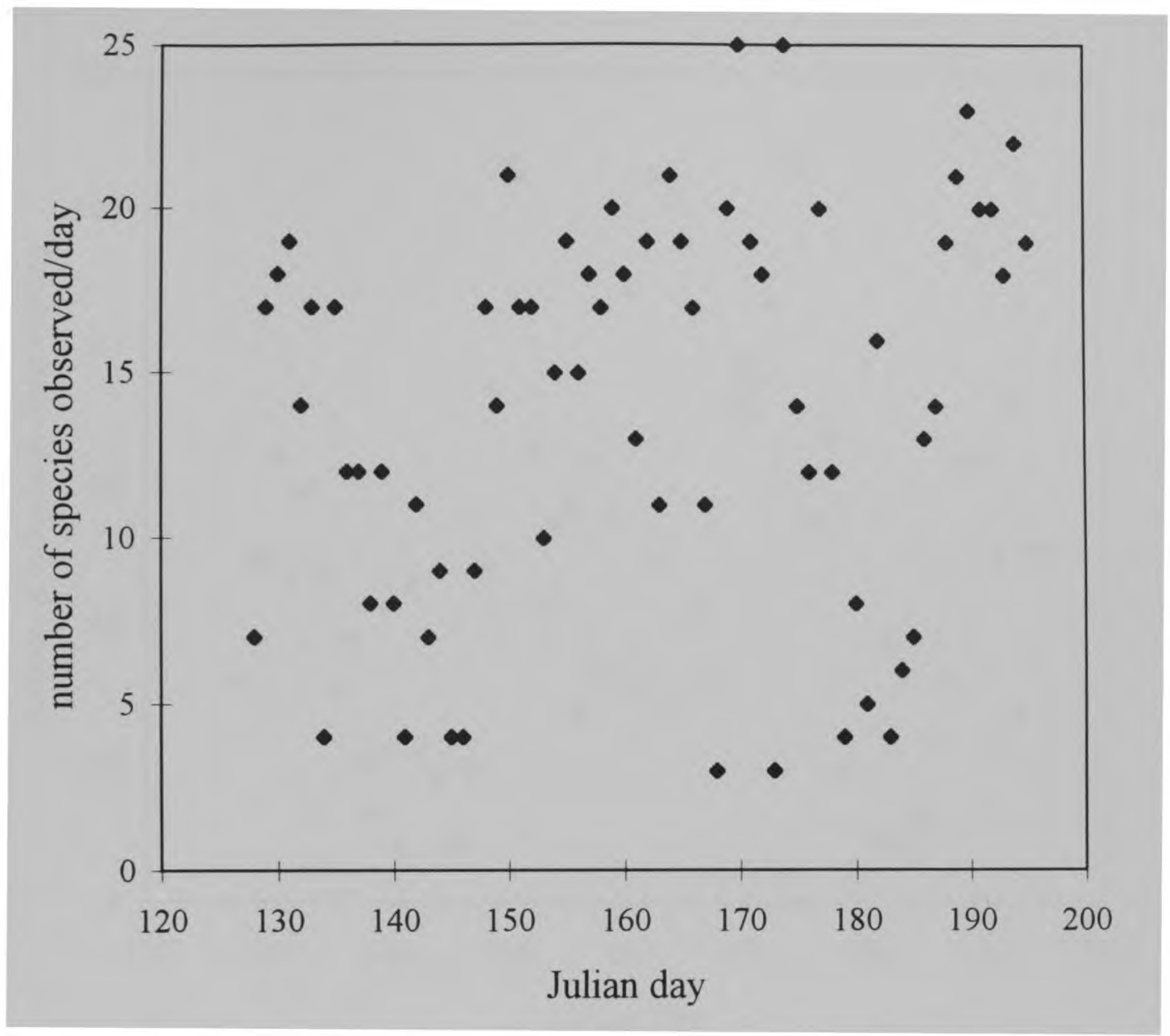

Figure 5. The relationship between the Julian day and the number of species observed. 


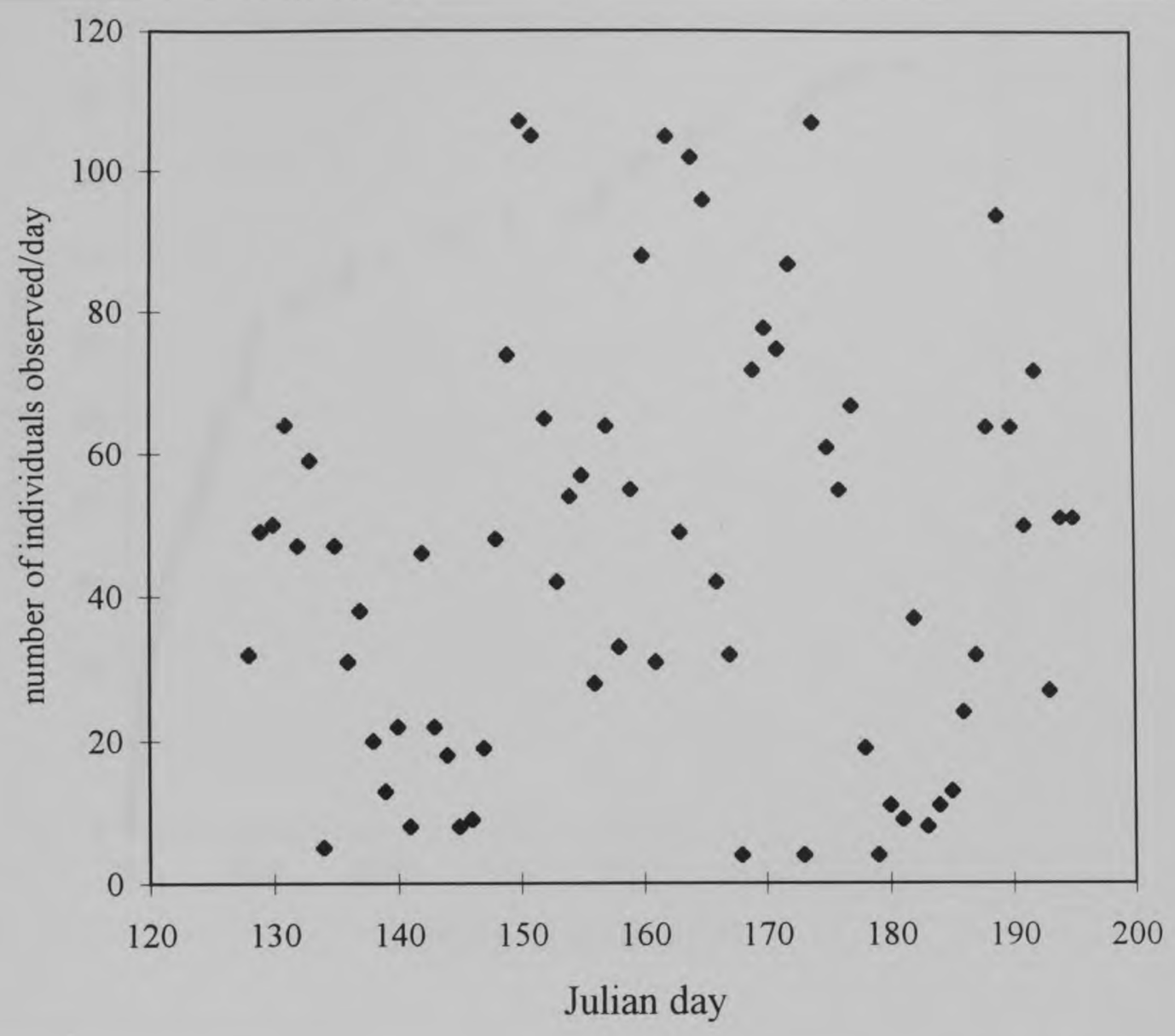

Figure 6. The relationship between the Julian day and the number of individuals observed. 


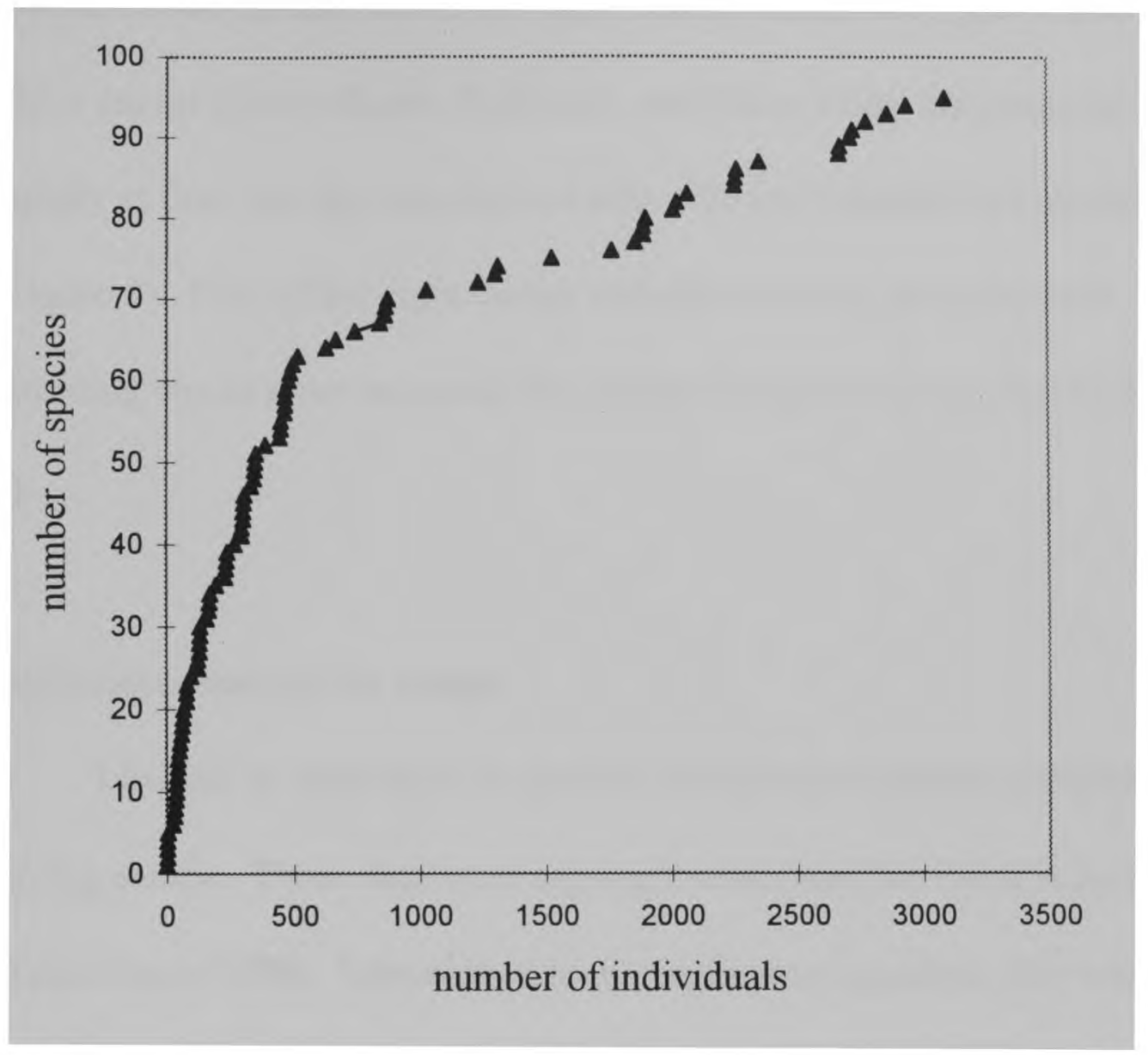

Figure 7. Species accumulation curve using all methods and data collected. 
species accumulation curves for each locality sampled (Figure 8 and 9).

Three camps (Burro-Burro, Kabocalli, and Three Mile) accumulated species rapidly at first, but the rates slowed after 200 individuals were obtained (Figure 8). Five of the eight camps indicate that data for continued sampling would have increased the number of species encountered (Figure 9).

\section{Differences among the camps}

I looked at differences in species richness and species evenness among camps. These data were log-log transformed for linear regression (TableCurve 1989). I developed linear regression equations that were standardized by the number of individuals caught (Figure 10 and 11). Equal numbers of individuals from the four methods at every camp were used in the comparison. At all camps there was a significant positive relationship between the number of individuals and the number of species (Table 4).

The eight camps shared a similar, but not identical, pattern of species accumulation.

I determined the differences among the linear equations by comparing their slopes. I used an analysis of covariance and found a significant 


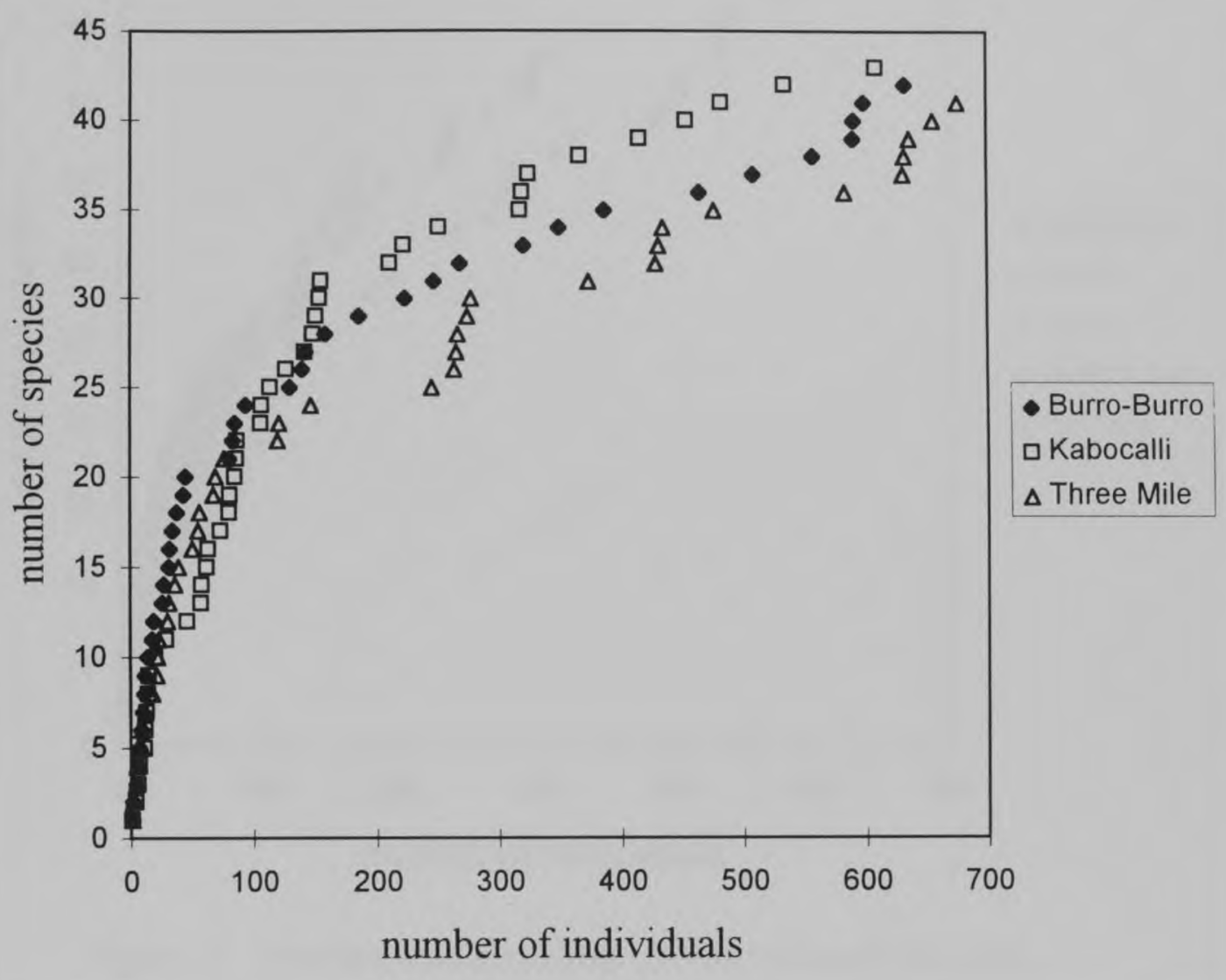

Figure 8. Species accumulation curves using all the data collected for three locations (Burro-Burro, Kabocalli, and Muri Scrub). 


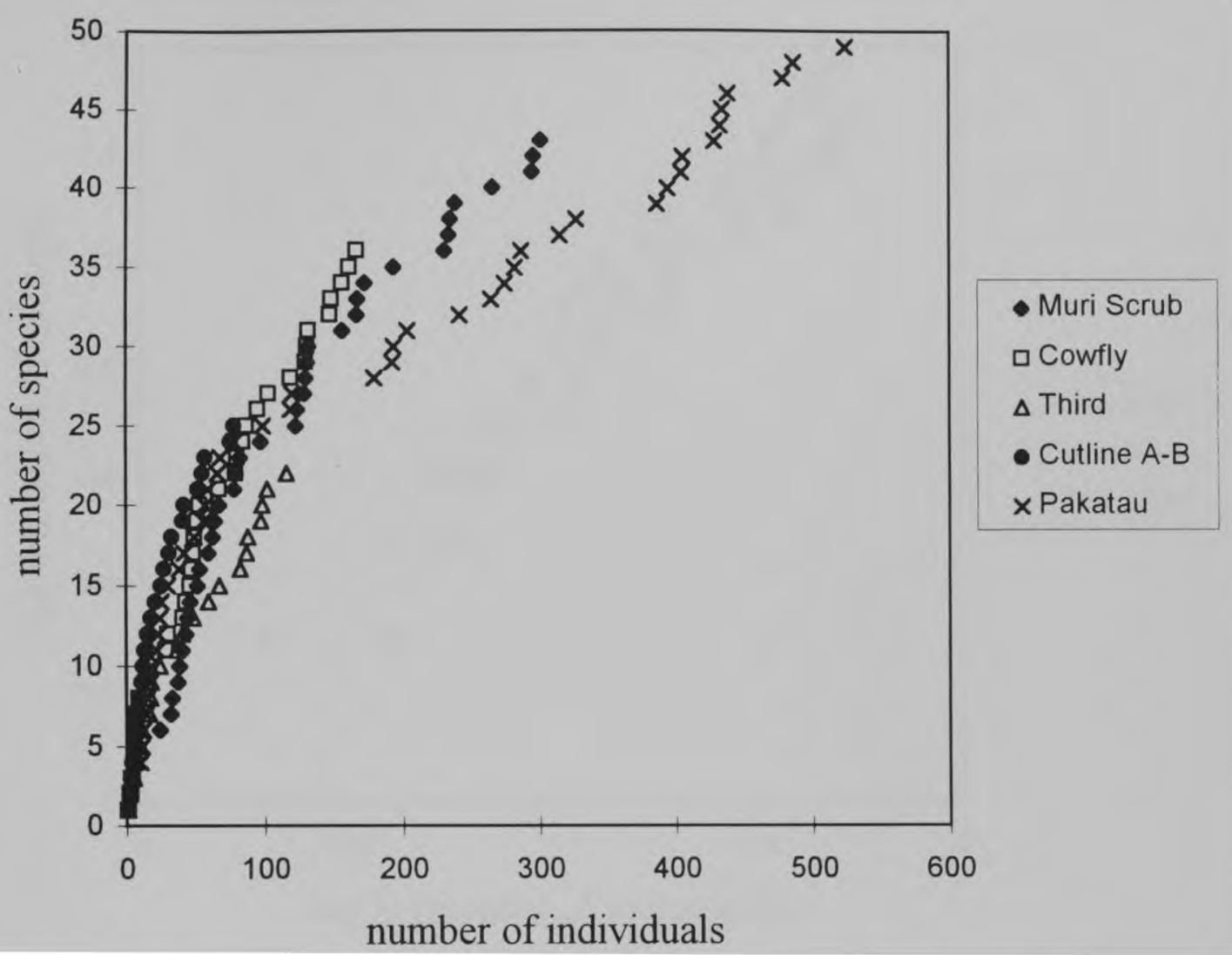

Figure 9. Species accumulation curves using all the data collected for five locations sampled (Muri Scrub, Cowfly, Third, Cutline A-B, and Pakatau). 


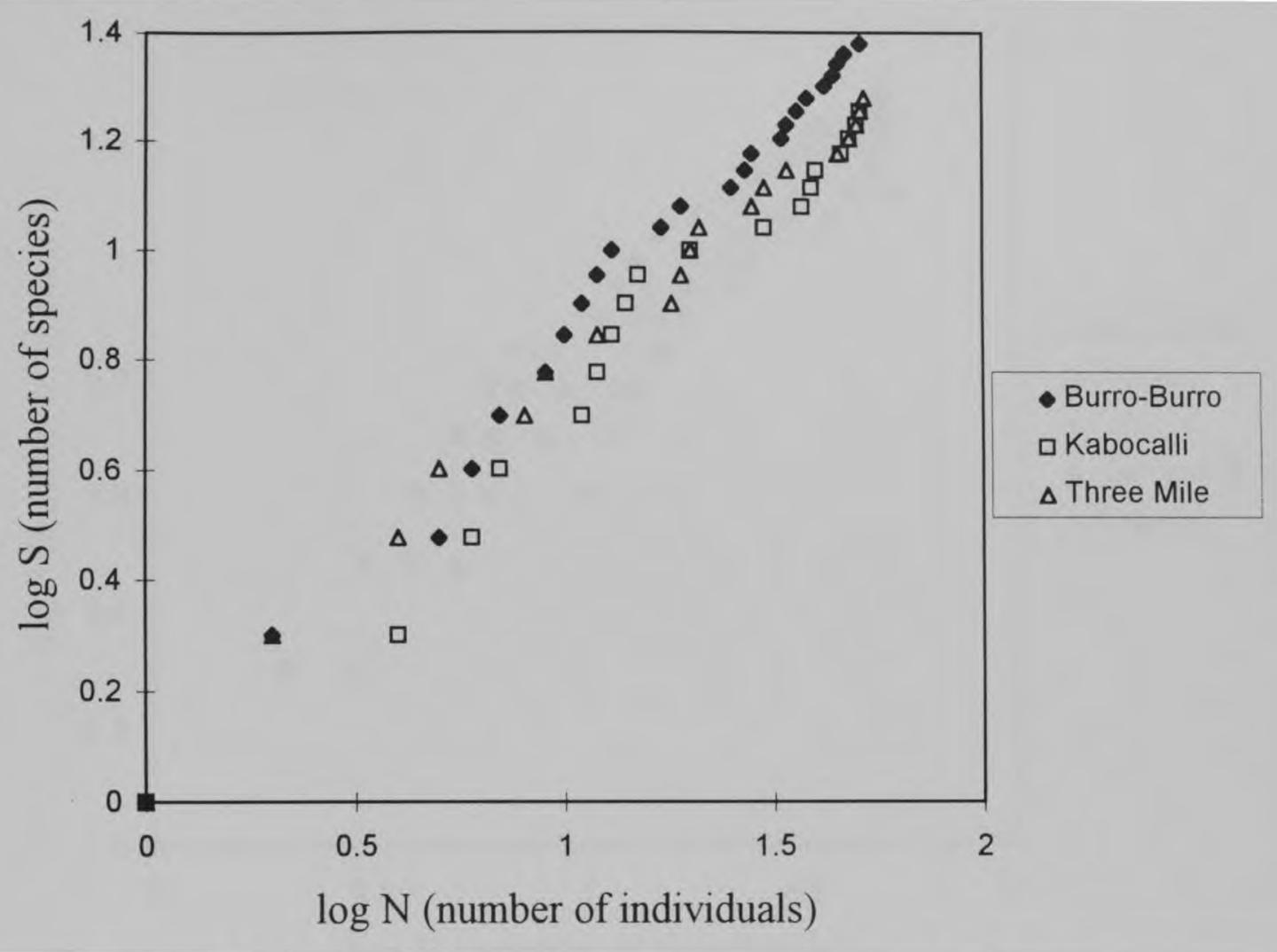

Figure 10. Species accumulation regression lines for three locations sampled standardized by the number of individuals caught (Burro-Burro, Kabocalli, and Three Mile). 


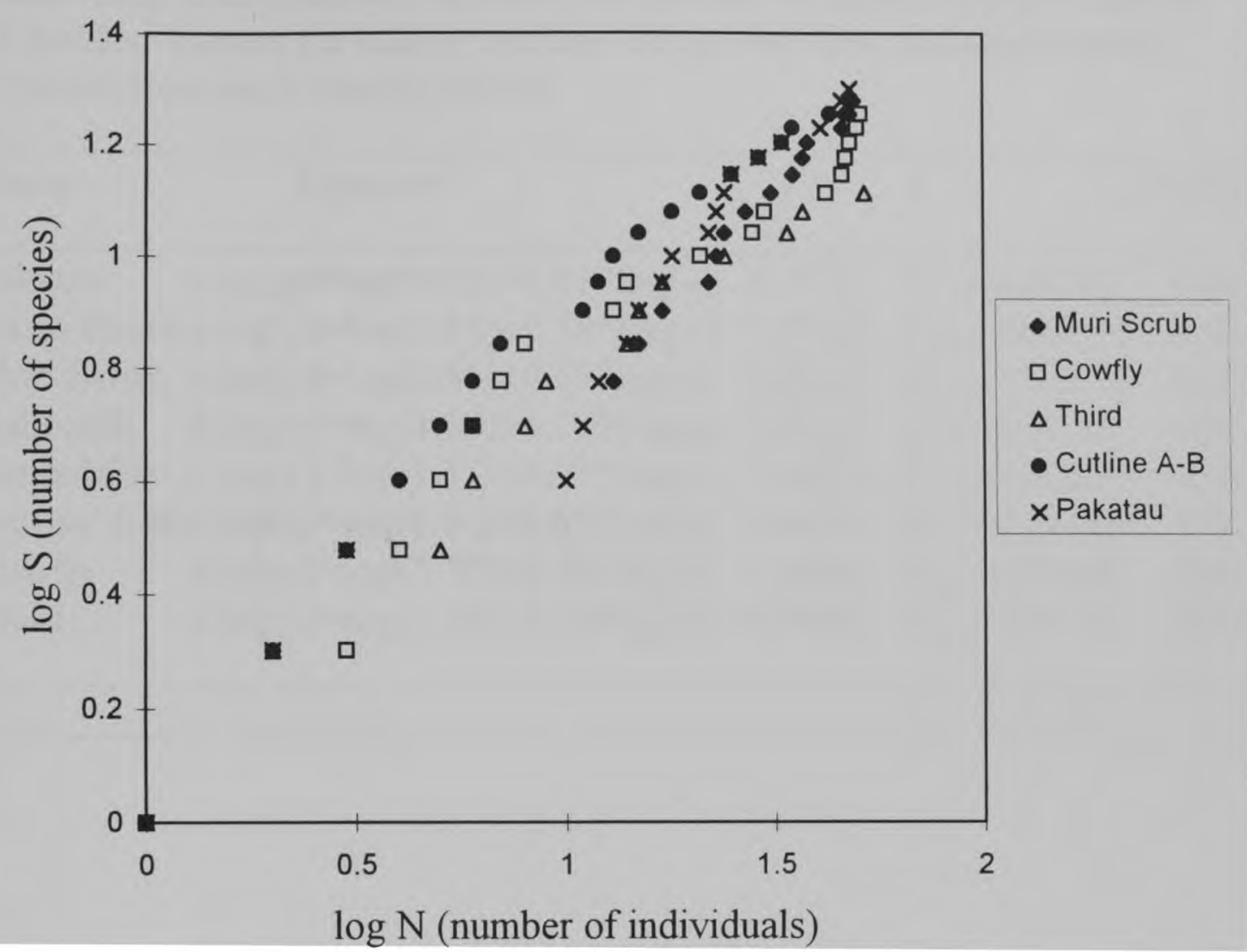

Figure 11. Species accumulation regression lines for five locations sampled standardized by the number of individuals (Muri Scrub, Cowfly, Third, Cutline A-B, and Pakatau). 
Table 4. Comparison of the linear equations among camps. The relationship examined was between the number of individuals and number of species. Letters (in italics) indicate camps that were not significantly different from each other $(\mathrm{p}=0.05)$.

\begin{tabular}{lllll}
\hline Camp & Equation & $\mathrm{r}^{2}$ & $\mathrm{~F}$ & $\mathrm{p}$-value
\end{tabular}

\begin{tabular}{lllll}
\hline Pakatau & $a \log (\mathrm{y})=\log (0.93)+0.81 * \log (\mathrm{x})$ & 0.9734 & $\mathrm{~F}_{1,19}=658.78$ & 0.01 \\
Burro-Burro $a \log (\mathrm{y})=\log (1.16)+0.78 * \log (\mathrm{x})$ & 0.9922 & $\mathrm{~F}_{1,23}=2804.19$ & 0.01 \\
Muri Scrub & $a \log (\mathrm{y})=\log (0.96)+0.77 * \log (\mathrm{x})$ & 0.9844 & $\mathrm{~F}_{1,18}=1070.23$ & 0.01 \\
Kabocalli & $b \log (\mathrm{y})=\log (1.06)+0.71 * \log (\mathrm{x})$ & 0.9749 & $\mathrm{~F}_{1,17}=622.55$ & 0.01 \\
Three Mile & $c \log (\mathrm{y})=\log (1.31)+0.67 * \log (\mathrm{x})$ & 0.9872 & $\mathrm{~F}_{1,18}=1313.77$ & 0.01 \\
Cutline A-B & $c \log (\mathrm{y})=\log (1.91)+0.62 * \log (\mathrm{x})$ & 0.9877 & $\mathrm{~F}_{1,17}=1287.05$ & 0.01 \\
Cowfly $\quad d \log (\mathrm{y})=\log (1.70)+0.58 * \log (\mathrm{x})$ & 0.9696 & $\mathrm{~F}_{1,17}=509.98$ & 0.01 \\
Third $\quad d \log (\mathrm{y})=\log (1.69)+0.54 * \log (\mathrm{x})$ & 0.9691 & $\mathrm{~F}_{1,12}=344.78$ & 0.01
\end{tabular}


determine which slopes were different I used nonparametric multiple comparisons analysis (Zar, 1984). Many of the slopes were significantly different from one another (Table 4). Although the linear species accumulation pattern looked similar among the camps graphically, these data show that there are some significant differences among the linear equations.

I estimated the number of species (S) with $95 \%$ confidence intervals at a standardized number of individuals $(\mathrm{N}=50)$ to compare species richness among camps (Figure 12). The camps were compared at 50 individuals because that was the highest common number of individuals that all the camps shared taking equal amount from each method. The camps varied in their species estimates (S) and differences in the estimation of species richness among camps were significant. All the estimates fell within a large range of 14.08 and 24.29 species.

I also compared species evenness among the camps using standardized rank abundance graphs (Figure 13 and 14). A pattern of many rare species and few common species was characteristic of all the camps (Magurran 1988). Although there are similarities in the abundances of species the actual number of species in different among the camps. 


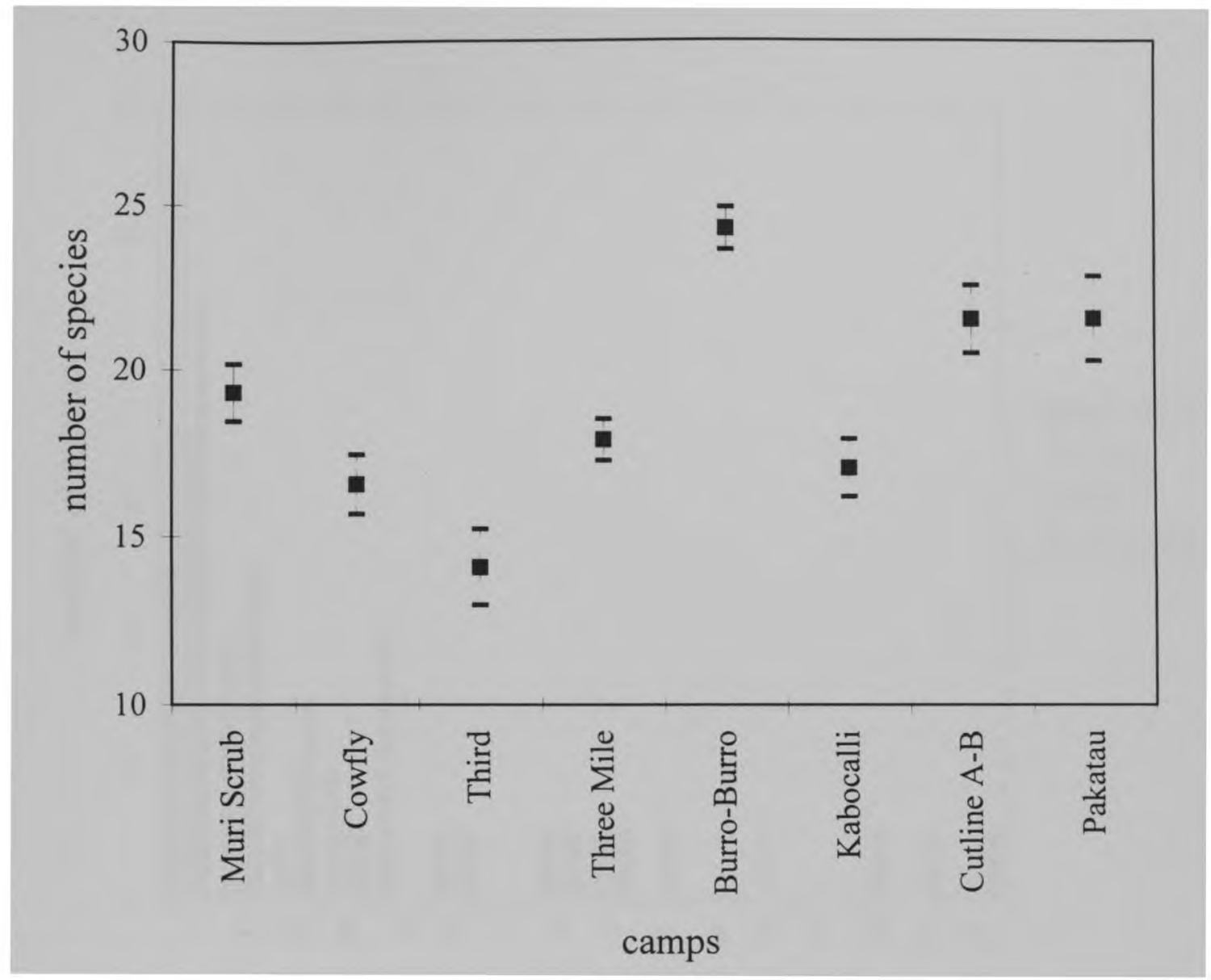

Figure 12. Comparison of the estimated number of species (S) with $95 \%$ confidence intervals using the linear equations among camps. All estimates were standardized to 50 individuals. 


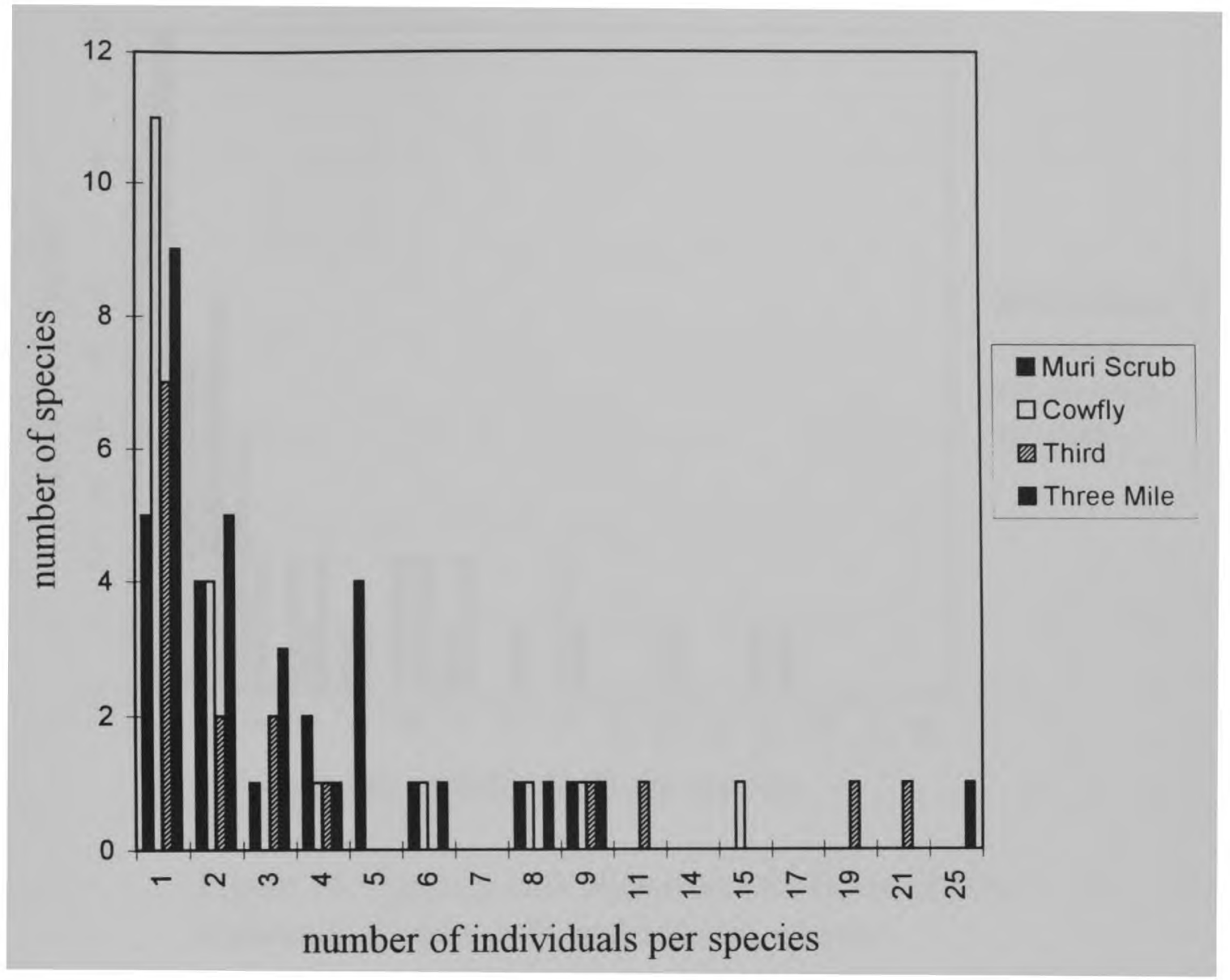

Figure 13. Species rank abundance for Muri Scrub, Cowfly, Third, and Three Mile camps. 


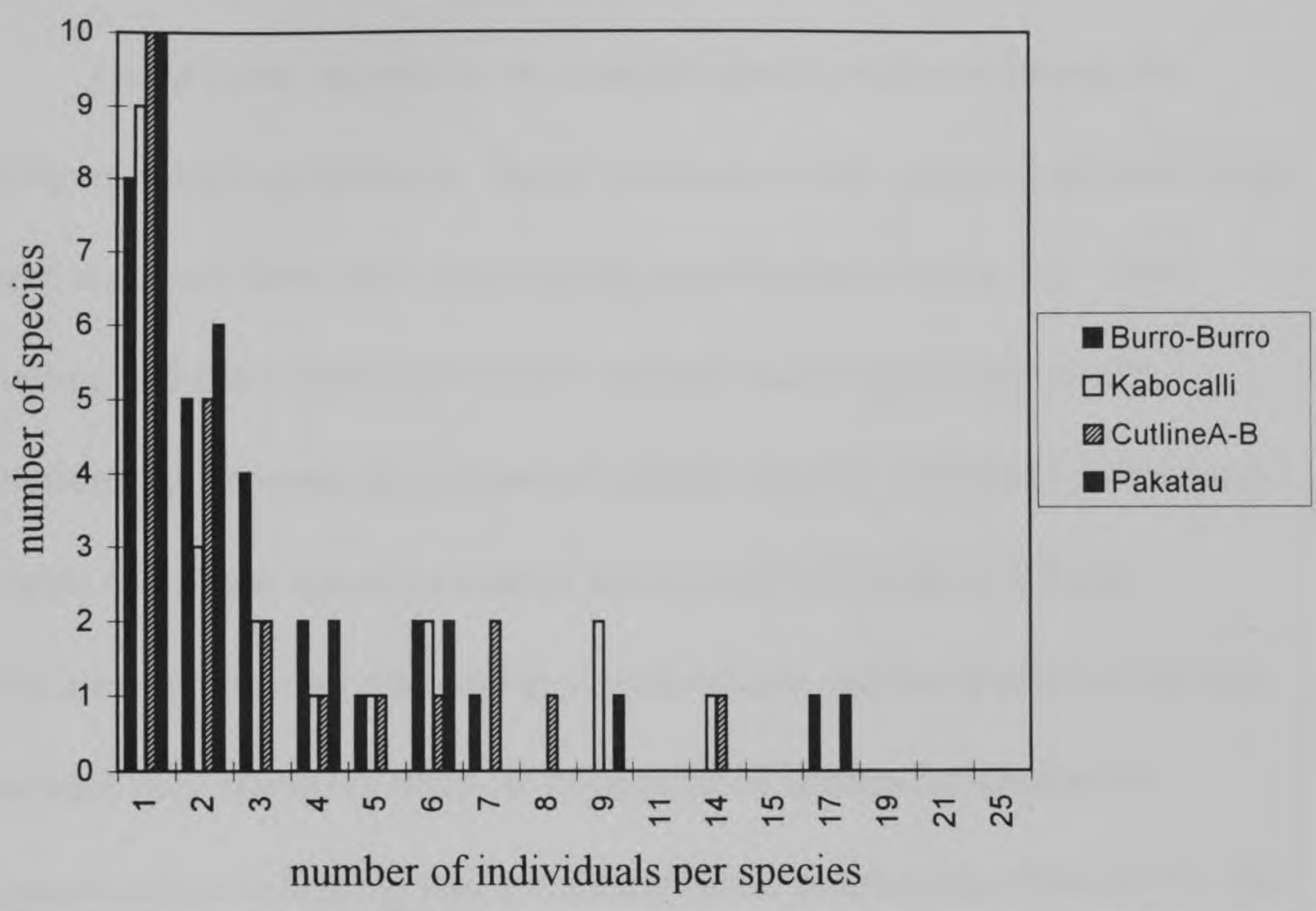

Figure 14. Species rank abundance for Burro-Burro, Kabocalli, Cutline A-B, and Pakatau camps. 
I used linear regression to compare species richness among the different sampling methods. Equal numbers of individuals from each camp were used and these data were log-log transformed (Figure 15). Each method and the combination of all methods had a significant positive relationship between the number of species and the number of individuals (Table 5). Night visual encounter survey and DVES show a linear relationship between the number of individuals and the number of species because they started to reach an asymptote in species accumulation. Opportunistic collecting had a different linear relationship than DVES and NVES. There is an initial slope where species were being accumulated at a very slow rate. Leaf litter plots needed additional sampling because the relationship between the number of individuals and number of species were still unknown.

I compared the slopes among the different methods to determine the differences among the equations. An analysis of covariance found significant differences among the slopes of the linear regression equations $\left(\mathrm{F}_{3,94}=543.75, \mathrm{p}=0.01\right)$ (Zar 1984). I used nonparametric multiple comparisons analysis to examine the differences among the methods and 


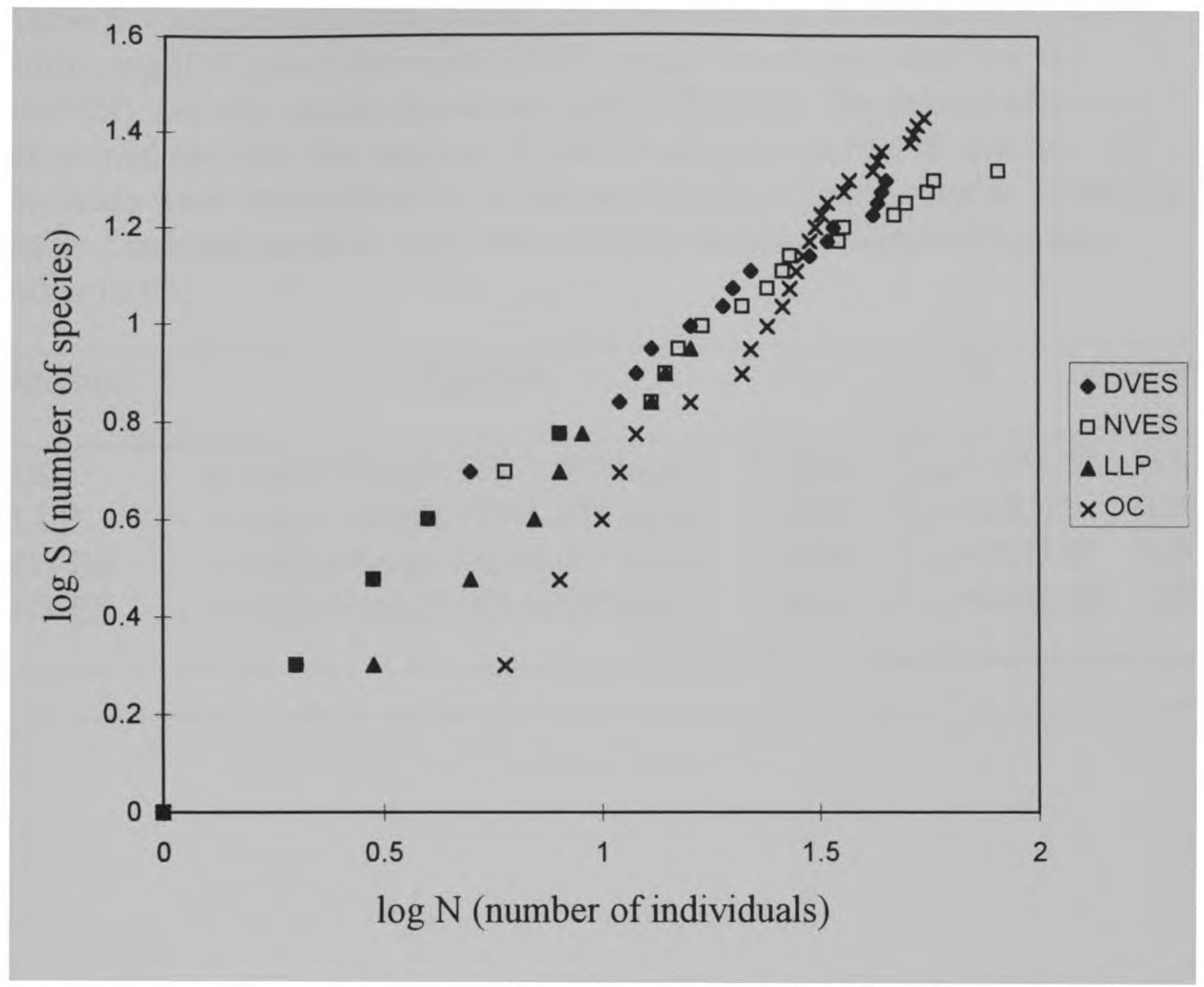

Figure 15. The relationship between $\log \mathrm{N}$ and $\log \mathrm{S}$ for each method: day visual encounter survey (DVES), night visual encounter survey (NVES), leaf litter plots (LLP), and opportunistic collecting $(\mathrm{OC})$ standardized by using equal numbers of individuals. 
Table 5. Comparison of the linear equations among methods: opportunistic collecting (OC), leaf litter plots (LLP), night visual encounter survey (NVES), and day visual encounter survey (DVES). The relationship was examined between the number of individuals and number of species. All methods were standardized to a common number of individuals. Letters (in italics) indicate methods that were not significantly different from each other (0.05).

Method Equation $\mathrm{r}^{2} \quad \mathrm{~F} \quad \mathrm{p}$-value

$\mathrm{OC}$ $a \log (\mathrm{y})=\log (0.37)+1.07 * \log (\mathrm{x})$

$0.9808 \quad F_{1,26}=1275.52$

LLP $b \log (\mathrm{y})=\log (0.79)+0.87 * \log (\mathrm{x})$

$0.9867 \quad F_{1,8}=520.21$

0.01

DVES

$c \log (\mathrm{y})=\log (1.63)+0.65 * \log (\mathrm{x})$

$0.9899 \quad F_{1,19}=1763.87$

NVES

$d \log (\mathrm{y})=\log (2.19)+0.52 * \log (\mathrm{x})$

0.993

$F_{1.41}=5804.20$

0.01 
discovered all methods were significantly different from each other. The opportunistic collecting slope was different from NVES $\left(q_{4,94}=62.36\right.$, $\mathrm{p}=0.05)$, DVES $\left(\mathrm{q}_{4,94}=32.33, \mathrm{p}=0.05\right)$, and plots $\left(\mathrm{q}_{4,94}=4.32, \mathrm{p}=0.05\right)$. The leaf litter plots slope was different from NVES $\left(\mathrm{q}_{4,94}=7.68, \mathrm{p}=0.05\right)$ and DVES $\left(\mathrm{q}_{4,94}=4.72, \mathrm{p}=0.05\right)$. The DVES slope was different from NVES $\left(\mathrm{q}_{4}\right.$, $\left.{ }_{94}=13.04, p=0.05\right)($ Zar 1984). The analysis suggests that the methods accumulate species at different rates.

Species richness was compared among the methods standardized by the number of individuals. The number of species (S) was predicted for each method at 16 individuals, the largest number of individuals without extrapolation using the linear regression equations (Figure 16). The species estimations ranged between 9.36 and 9.74 individuals for NVES, DVES or leaf litter plots at the 0.05 level. However, the number of species estimated using opportunistic collecting was lower ( 7.35 species) compared to the other methods at the 0.05 level.

I estimated the species richness for three methods at a higher number of individuals by excluding leaf litter plots. The number of species (S) was predicted for three of the methods at 56 individuals using regression equations (Figure 17). Leaf litter plots did not collect enough individuals to 


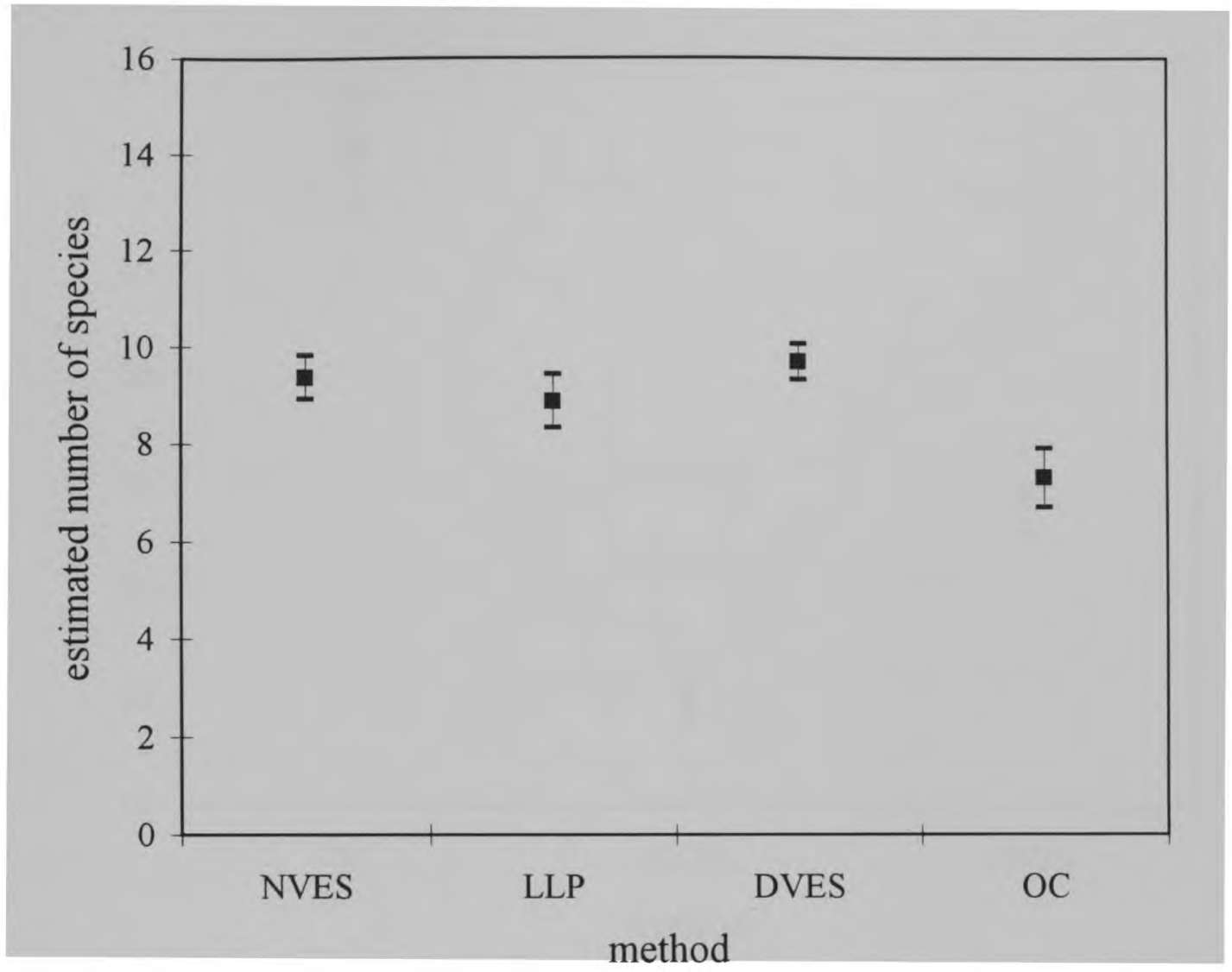

Figure 16. Comparison of the estimated number of species with $95 \%$ confidence intervals among methods: day visual encounter survey (DVES), night visual encounter survey (NVES), leaf litter plots (LLP), opportunistic collecting (OC) at 16 individuals. 


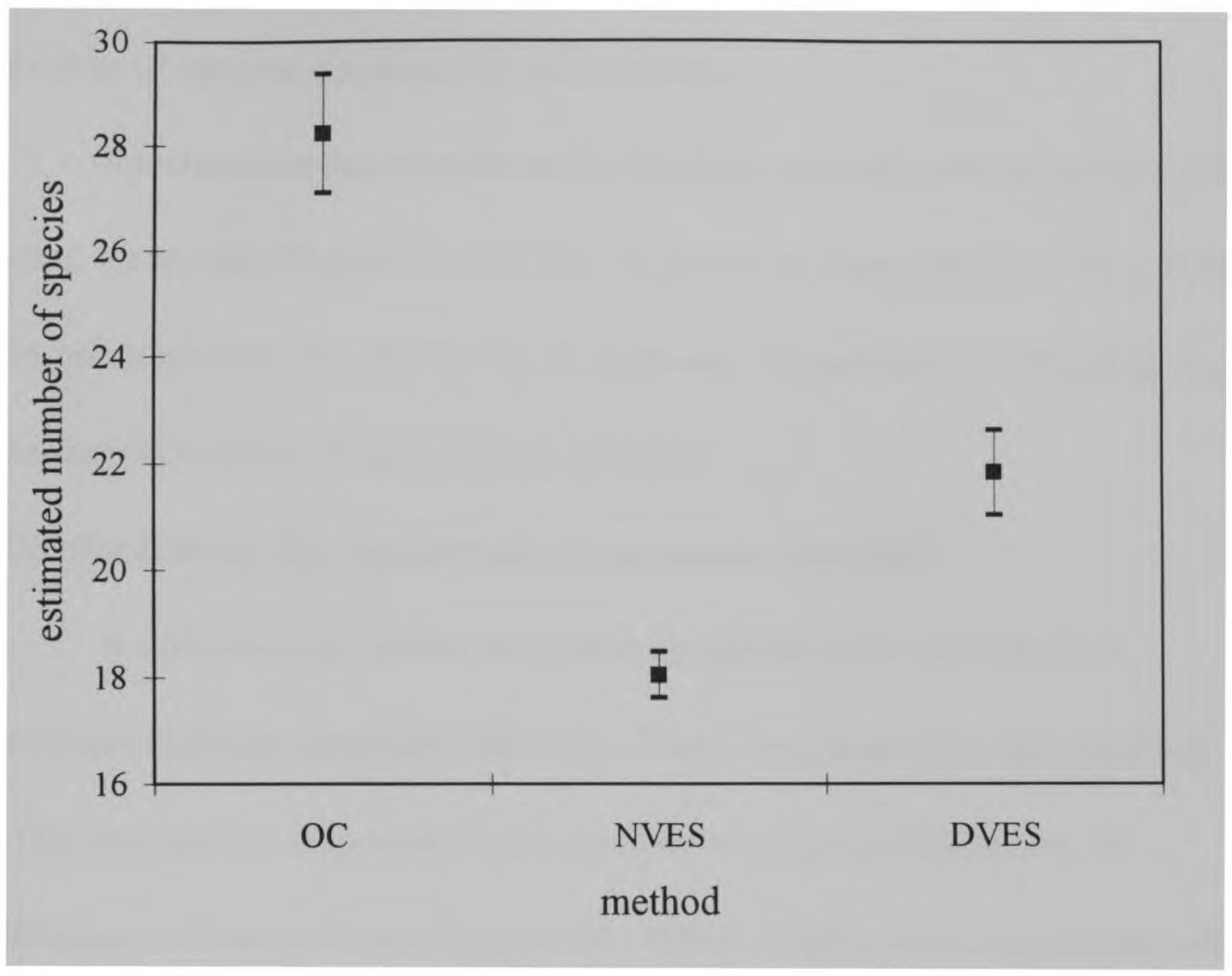

Figure 17. Comparison of the estimated number of species with $95 \%$ confidence intervals among methods: day visual encounter survey (DVES), night visual encounter survey (NVES), and opportunistic collecting (OC) at 56 individuals. 
be compared at this level. There was a significant difference between the number of species estimated by all methods.

Species abundance patterns for the four methods were also examined using these data (Figure 18 and 19). A pattern of many rare species and few abundant species was shown for all methods. Opportunistic collecting had the largest number of rare species collected.

\section{Standardized by the number of person-hours expended}

A second set of linear regression equations were calculated to compare different sampling methods. These equations were standardized using the number of person hours sampled to examine differences in efficiency of the methods (Figure 20). Effort in terms of person-hours was not recorded for opportunistic collecting so I made a conservative estimate of one person-hour expended each day per person for comparison among methods. Night visual encounter survey, DVES and opportunistic collecting reached an asymptote, so the relationship between the number of species and person-hours expended was linear on the log-log graph. Leaf litter plots were not sampled long enough to get a precise linear relationship between the number of species and person-hours. Every method had a 


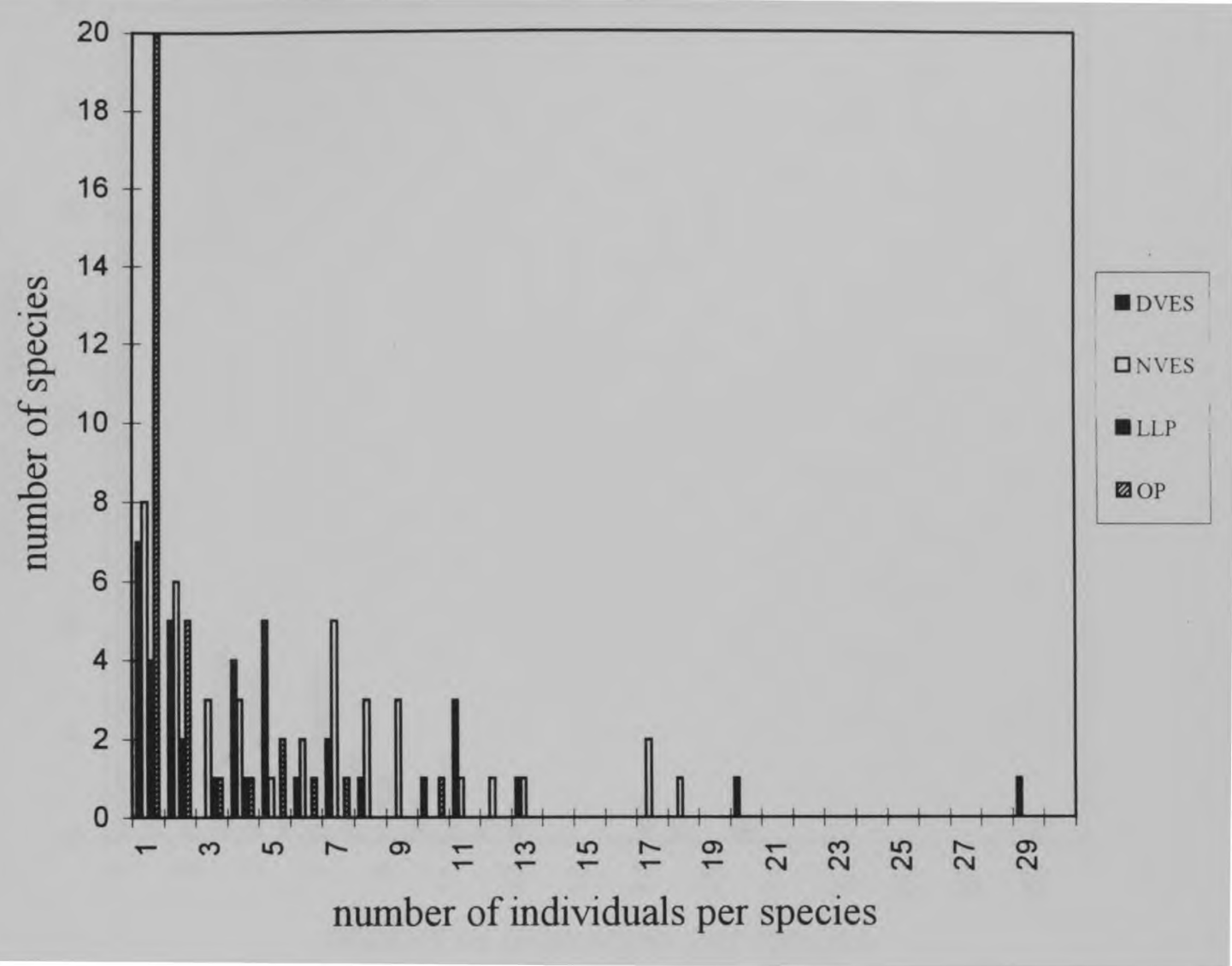

Figure 18. Species rank abundance for the methods: day visual encounter survey (DVES), night visual encounter survey (NVES), leaf litter plots (LLP), and opportunistic collecting $(\mathrm{OC})$ standardized by the number of individuals. 


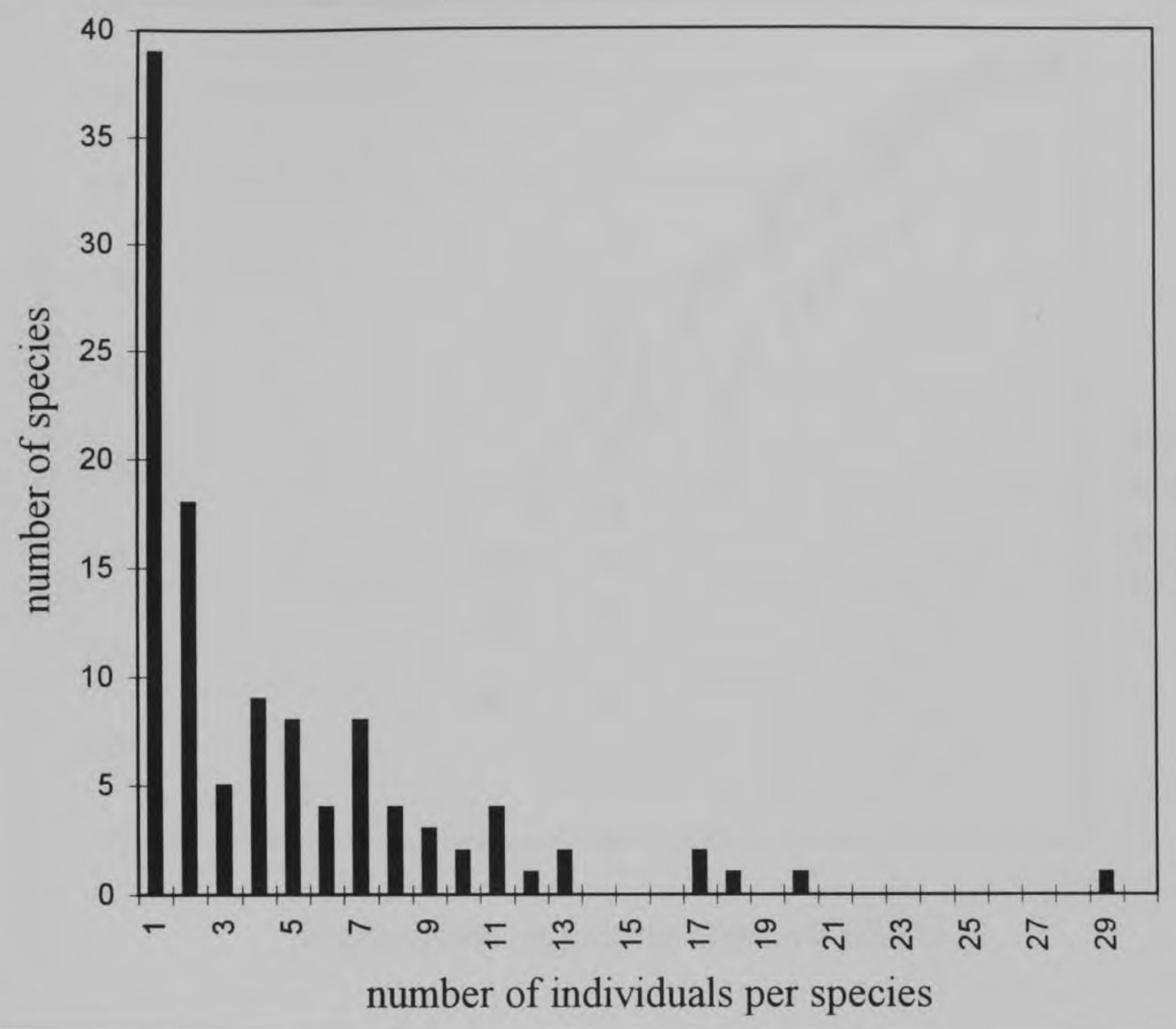

Figure 19. Species rank abundance using the number of individuals for all methods combined. 


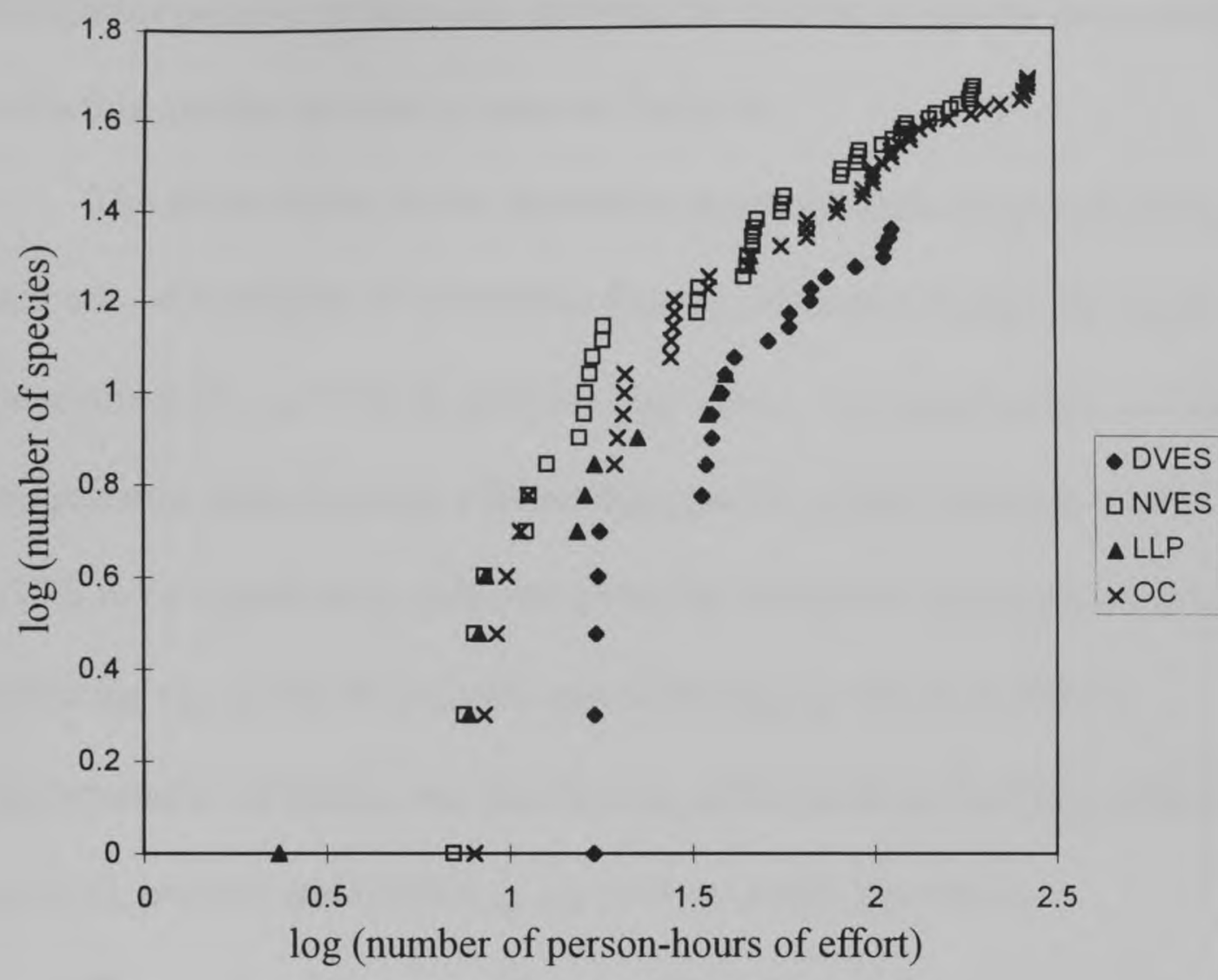

Figure 20. The number of person-hours and the number of species compared among methods: day visual encounter survey (DVES), night visual encounter survey (NVES), leaf litter plots (LLP), and opportunistic collecting (OC) standatdized by person-hours. 
significant positive relationship between the number of person-hours spent collecting and the number of species (Table 6).

The slopes of the linear regression equations were compared among methods. An analysis of covariance found a difference among the slopes of the methods $\left(\mathrm{F}_{3,124}=108.36, \mathrm{p}=0.01\right)$ (Zar 1984). A nonparametric multiple comparisons analysis using a found that species richness estimated with DVES to be significantly different from that estimated with opportunistic collecting $\left(\mathrm{q}_{4,124}=26.09, \mathrm{p}=0.05\right)$ and $\operatorname{NVES}\left(\mathrm{q}_{4,124}=22.61, \mathrm{p}=0.05\right)$.

Opportunistic collecting was significantly different from leaf litter plots $\left(\mathrm{q}_{4}\right.$, $124=4.23, \mathrm{p}=0.05)$ and NVES $\left(\mathrm{q}_{4,124}=5.48, \mathrm{p}=0.05\right)($ Zar 1984 $)$.

The number of species (S) was predicted for each method at 56 person hours of effort. This number was within the observed range for person hours of effort for each method and the combination of all methods (Figure 21) Night visual encounter survey and opportunistic collecting had higher species estimates (19-23 species) than the DVES and leaf litter plots (11-15 species).

The species richness of three methods was also compared at a high number of person-hours by excluding leaf litter plot sampling. The number of species was estimated at 136 person-hours of effort and found to be 
Table 6. Comparison of the linear equations among methods: opportunistic collecting (OC), leaf litter plots (LLP), night visual encounter survey (NVES), and day visual encounter survey (DVES). The relationship examined was the number of person-hours and number of species standardized by the number of person-hours collected. Letters (in italics) indicated methods that were not significantly different from each other (0.05).

Method Equation $r^{2}$ F p-value

DVES $a \log (\mathrm{y})=\log (0.40)+0.86^{*} \log (\mathrm{x})$

0.9419

$\mathrm{F}_{1,2}=340.54$

0.01

LLP

$a \log (\mathrm{y})=\log (0.74)+0.73 * \log (\mathrm{x})$

$0.9504 \quad F_{1,10}=172.67$

0.01

NVES

$b \log (\mathrm{y})=\log (2.02)+0.60 * \log (\mathrm{x})$

0.9723

$F_{1,44}=1506.65$

0.01

OC

$b \log (\mathrm{y})=\log (2.18)+0.56 * \log (\mathrm{x}) \quad 0.9639$

$F_{1,48}=1253.36$

0.01 


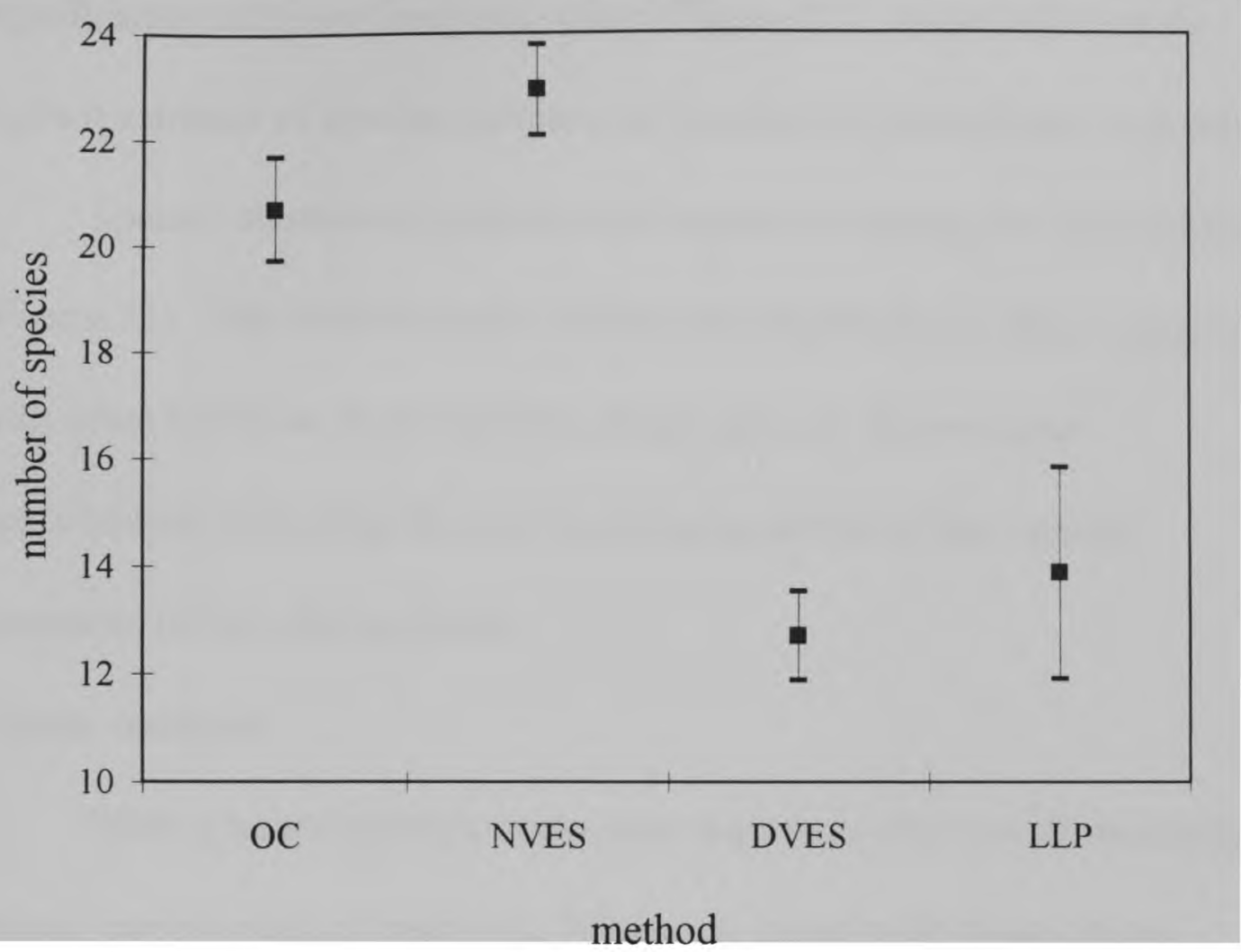

Figure 21. Comparison of the estimated number of species with $95 \%$ confidence intervals among methods: day visual encounter survey (DVES), night visual encounter survey (NVES), leaf litter plots (LLP), and opportunistic collecting $(\mathrm{OC})$ at 56 person-hours. 
significantly different from each other (Figure 22). Night VES had the highest estimate of species richness per number of person-hours expended.

Species abundance patterns were examined among the four methods

(Figure 23). The methods had a similar asymmetrical abundance pattern with some variation in the number of rare species. In particular, opportunistic collecting showed much higher levels of rare species compared to the other methods.

\section{Cluster analysis}

When presence-absence data were used to assess overall similarity among camps using all methods, Pakatau clustered with Burro-Burro, Cutline A-B clustered with Kabocalli, and these sites linked to Three Mile. Third and Cowfly were most similar and Muri Scurb differed from all other camps (Figure 24). The pattern generated by all methods (Figure 24) was not repeated using any single method alone (Figures 25-28). The relationship among the camps was different depending on the method used.

\section{Method efficiency}

The average number of individuals observed per person-hour was compared among methods (Table 7). These data had a log normal distribution with heterogeneous variances so nonparametric methods were 


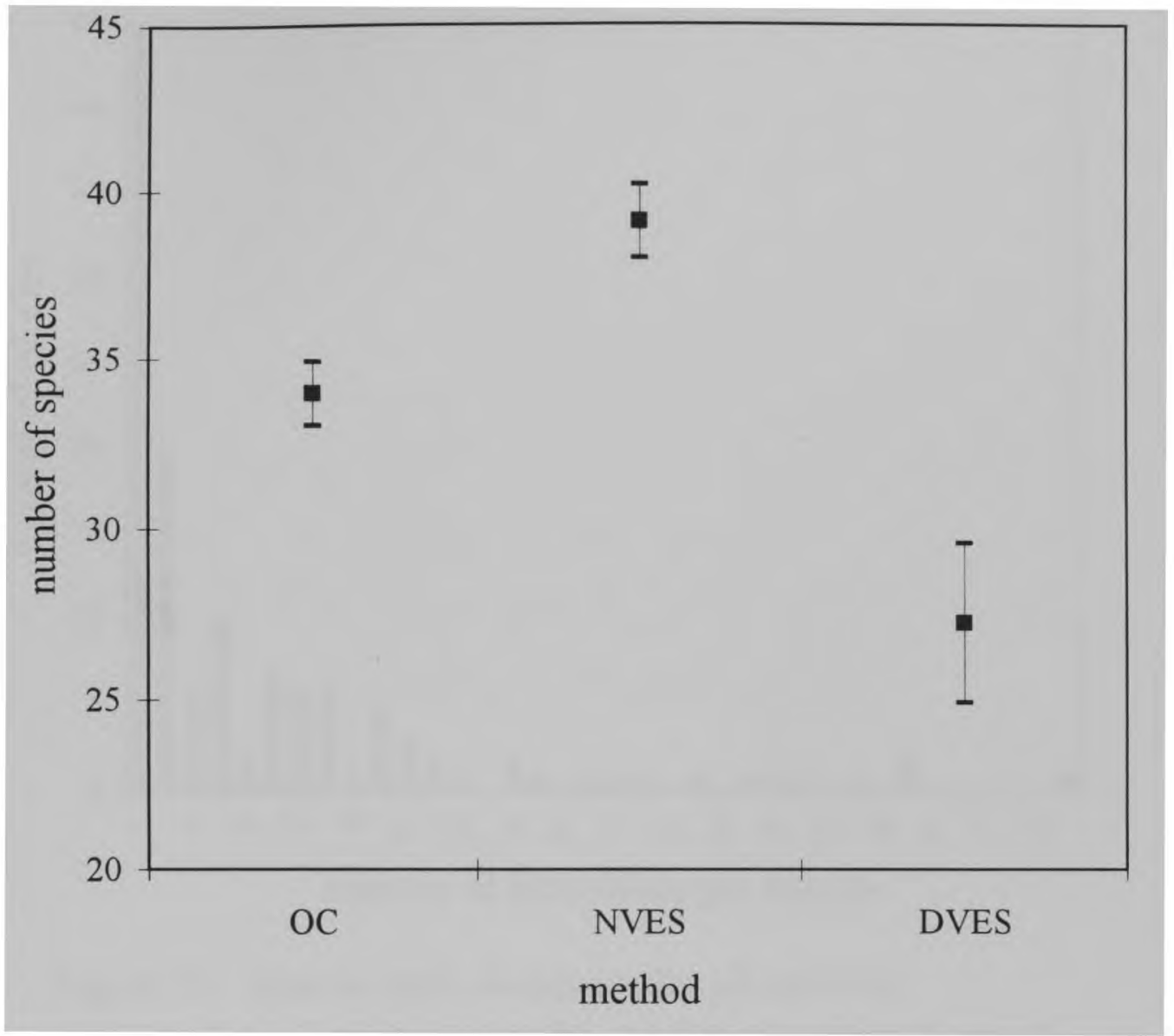

Figure 22. Comparison of the estimated number of species with $95 \%$ confidence intervals among methods: day visual encounter survey (DVES), night visual encounter survey (NVES), and opportunistic collecting (OC) at 136 personhours. 


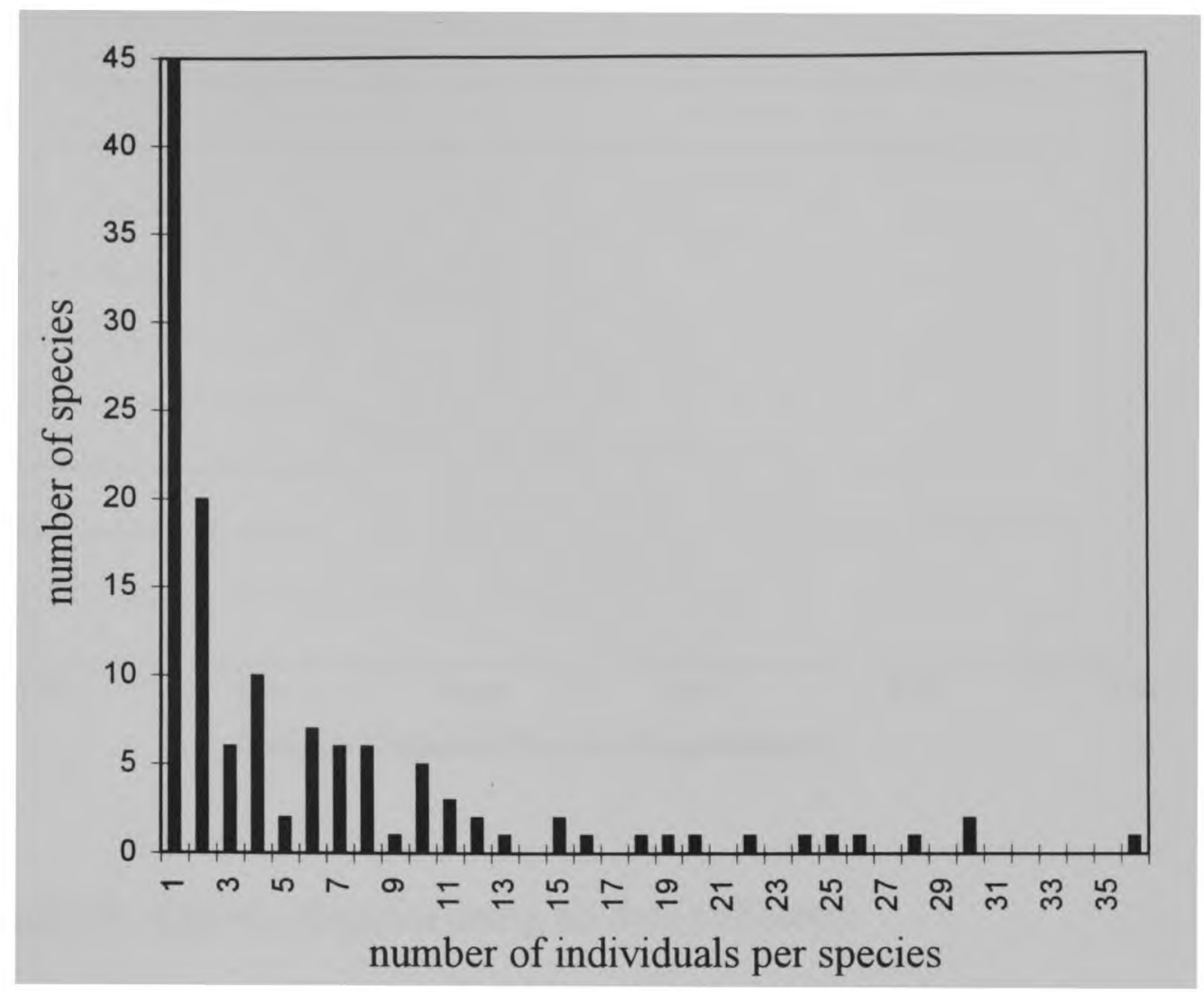

Figure 23. Species rank abundance for all methods combined standardized using the number of person- hours of effort. 


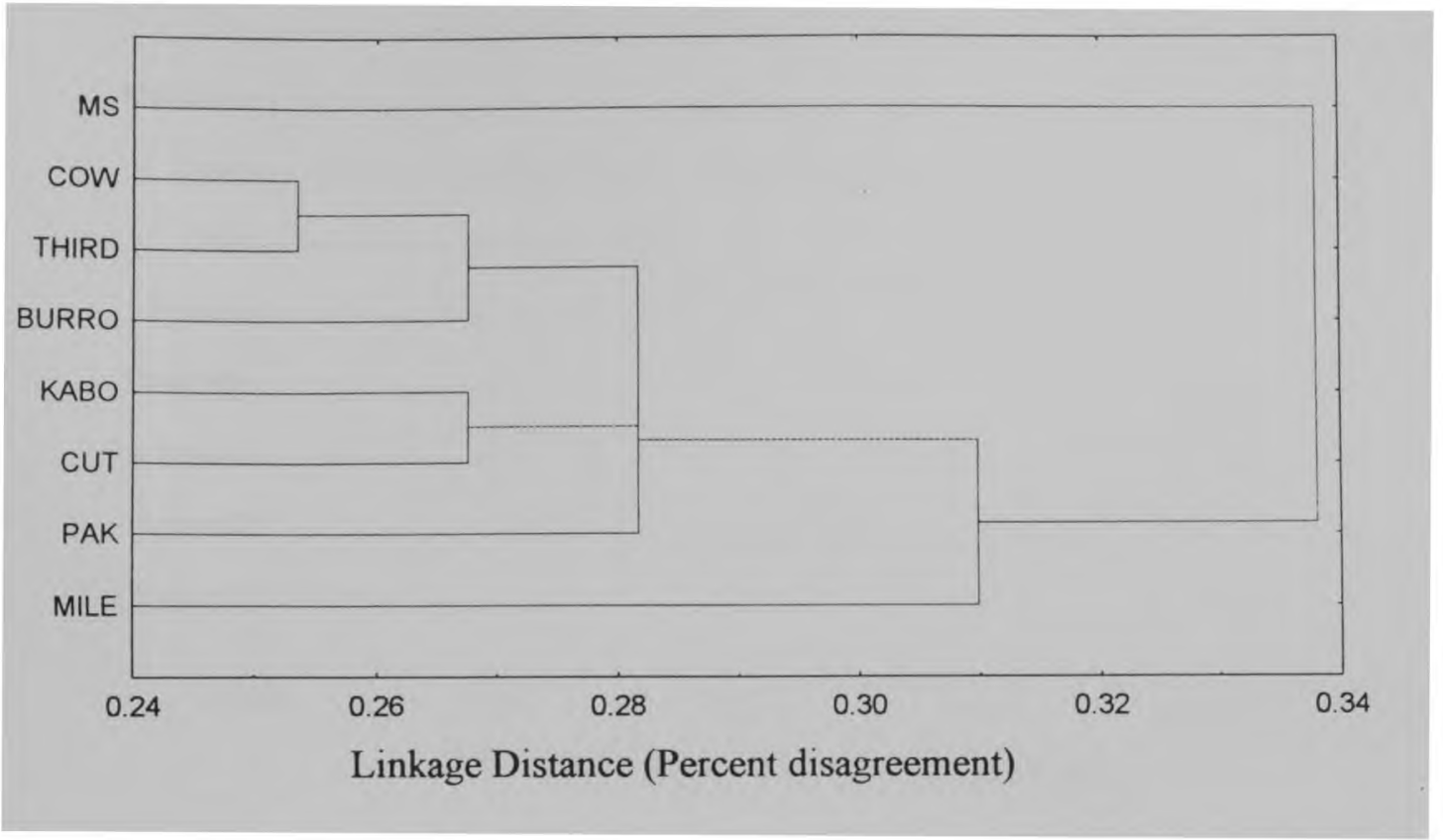

Figure 24. Cluster diagram using all data collected. 


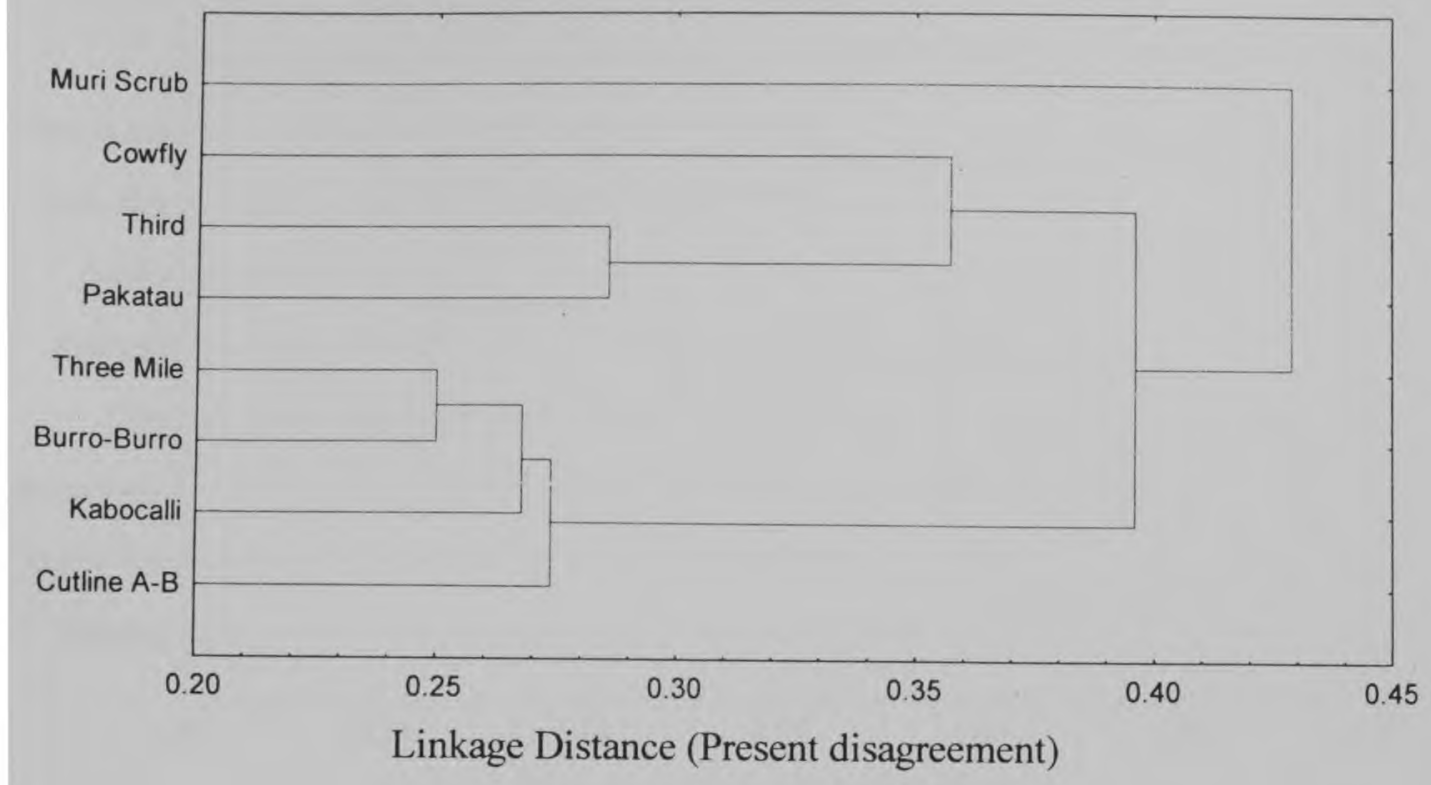

Figure 25. Cluster diagram using day visual encounter survey data collected. 


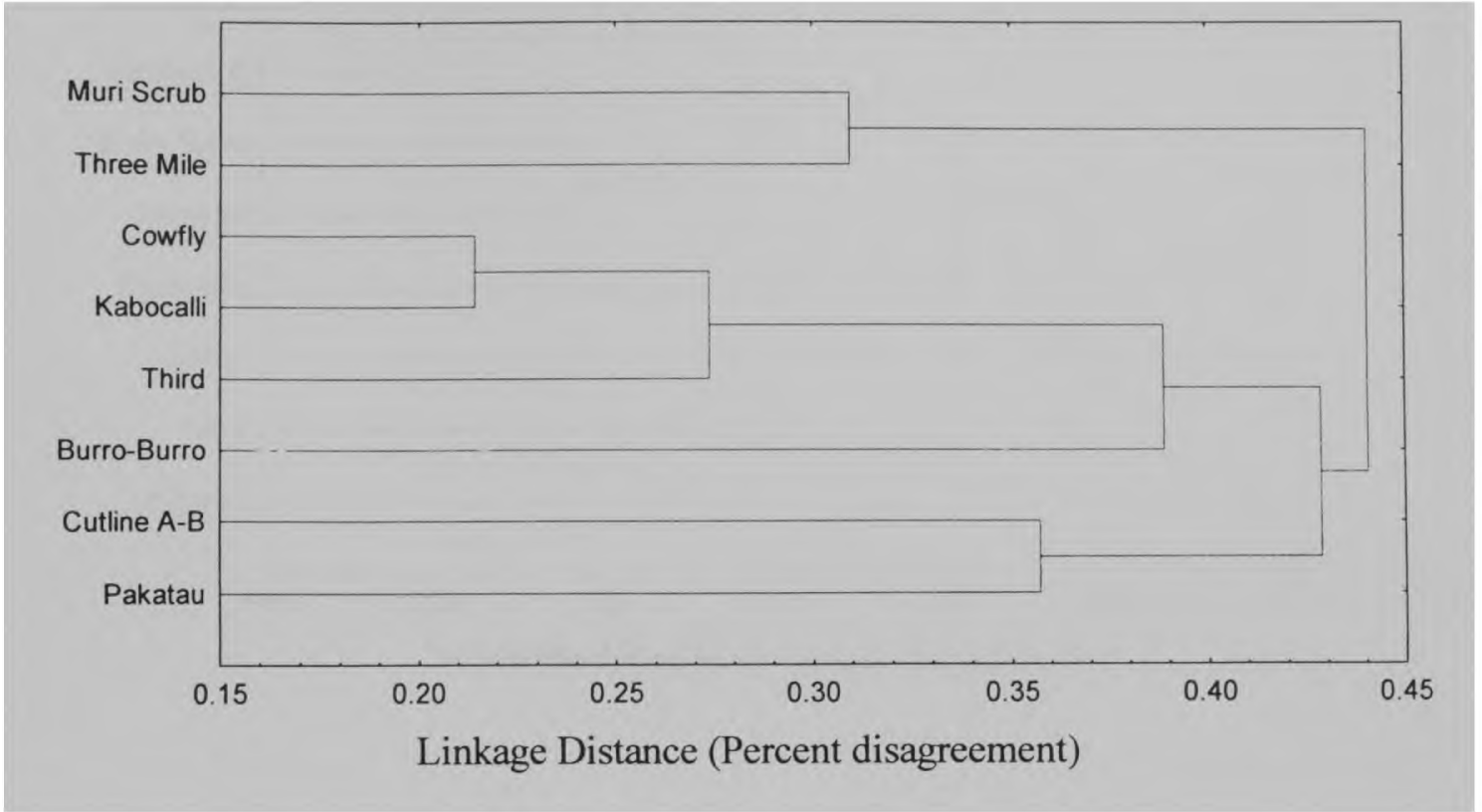

Figure 26. Cluster diagram using night visual encounter survey data collected. 


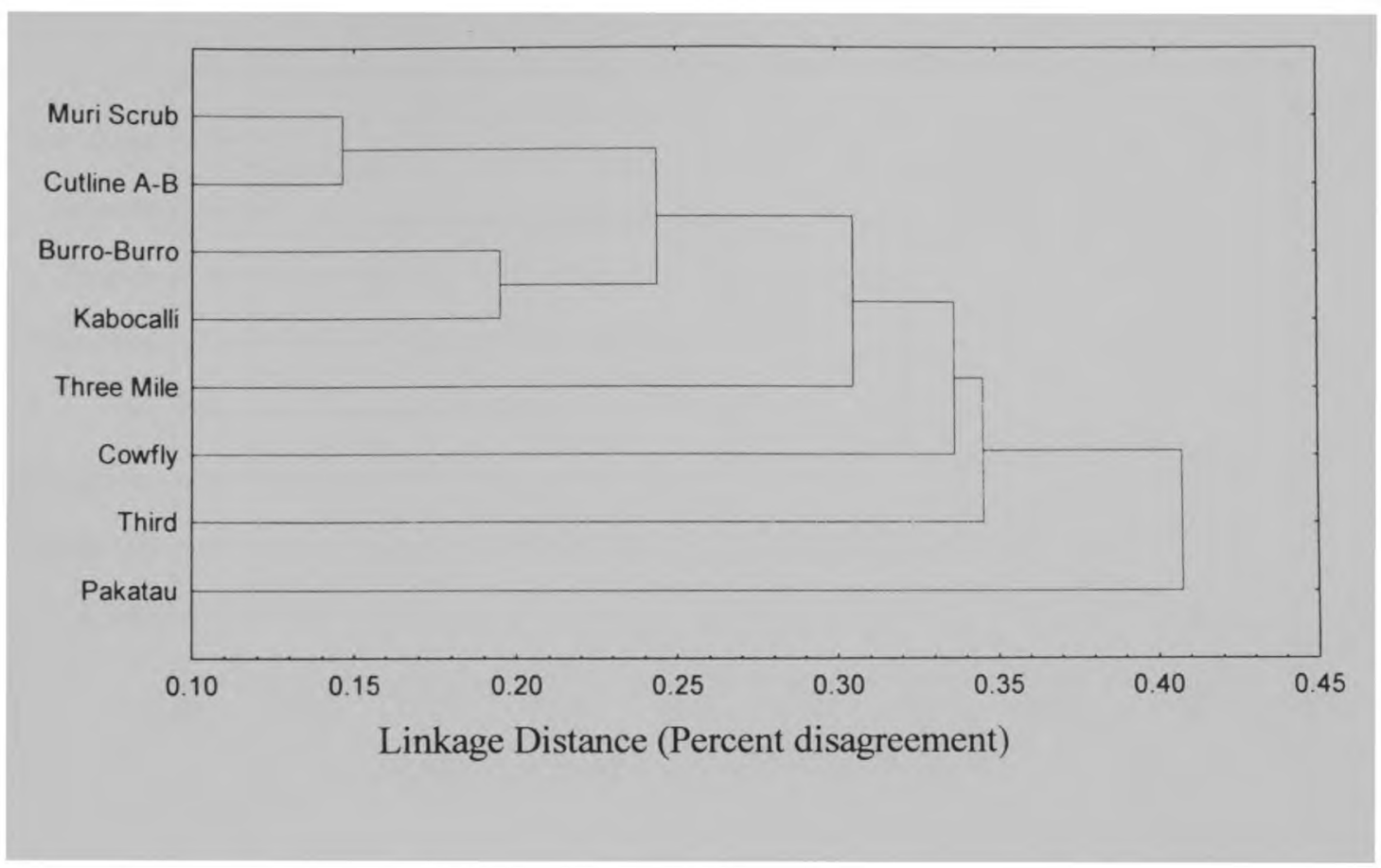

Figure 27. Cluster diagram using opportunistic collecting data. 


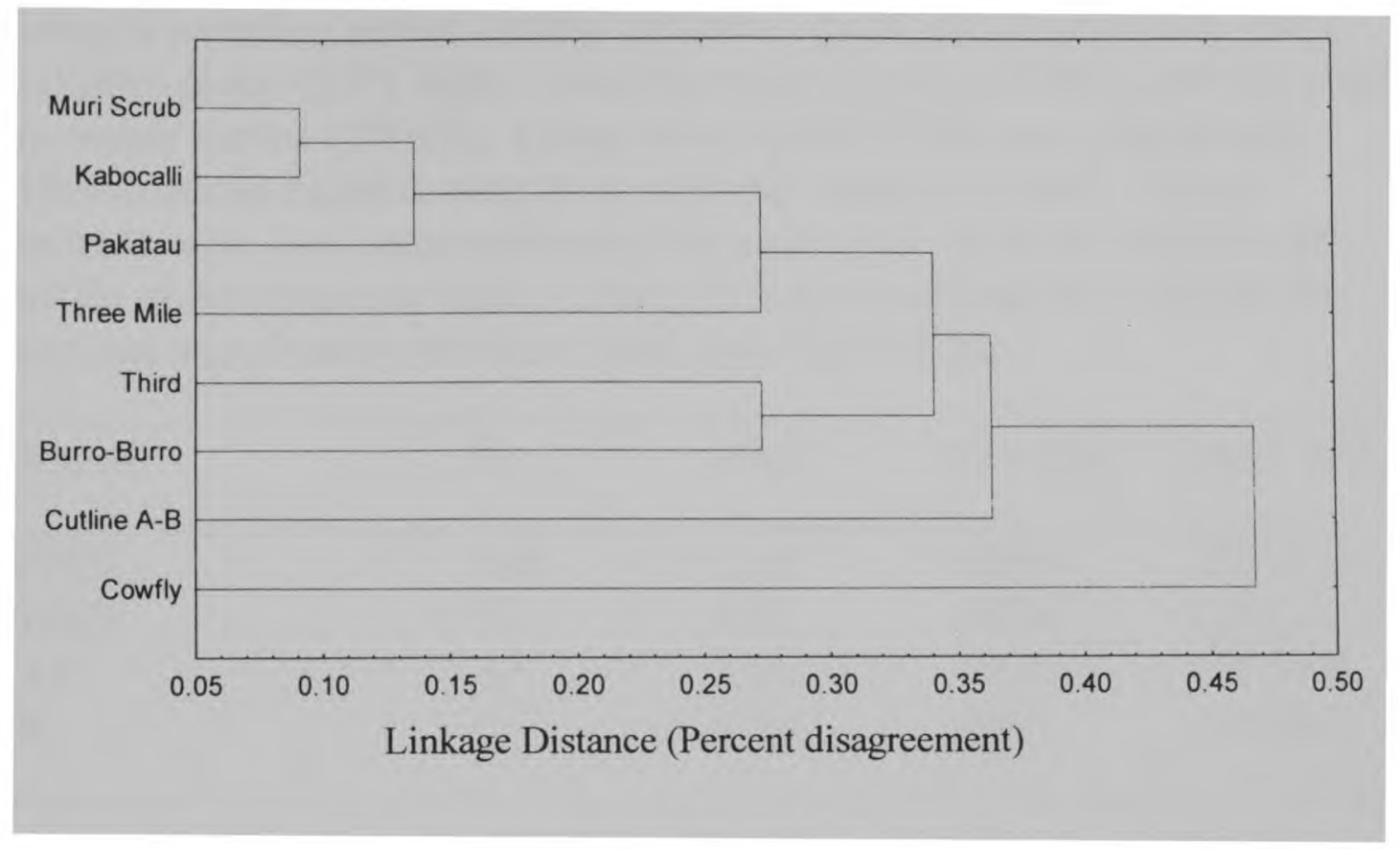

Figure 28. Cluster diagram using leaf litter plot data collected. 
Table 7. Comparison of the number of individuals caught per person hour during a sampling period among methods: opportunistic collecting (OC), leaf litter plots (LLP), night visual encounter survey (NVES), and day visual encounter survey (DVES). Using the Kruskal-Wallis test a significant difference was found among these methods at the 0.01 level. These methods were then compared using nonparametric multiple comparisons test for unequal sample sizes. Letter (in italics) indicate the methods that were not significantly different from each other $(0.05)$.

\begin{tabular}{lllll}
\hline Method & N & mean & Sum rank & Mean rank \\
\hline NVES & 140 & 2.14 & 32016 & $228.69 a$ \\
DVES & 91 & 1.37 & 16218.5 & $178.23 b$ \\
LLP & 77 & 1.18 & 13439.5 & $174.54 b$ \\
OC & 55 & 0.46 & 4392 & $79.86 c$ \\
\hline
\end{tabular}


used. The Kruskal-Wallis test found these data to be significantly different from each other at the 0.05 level $\left(\mathrm{H}^{\prime}=80.34\right)$. Nonparametric multiple comparisons using a Tukey-like test found NVES to be significantly different from all other methods at the 0.05 level. Day VES and leaf litter plot were significantly different from the other methods but not from each other at the 0.05 level. Opportunistic collecting was significantly different from all other methods at the 0.05 level. Night VES caught the largest number of individuals per unit of effort compared to the other methods. Opportunistic collecting was the least successful in catching individuals per unit of effort.

The number of species caught per person-hour was also compared among methods (Table 8). These data were log normally distributed and had heterogeneous variances so nonparametric methods were used. The Kruskal-Wallis test found these data to be significantly different from each other at the 0.05 level $\left(\mathrm{H}^{\prime}=78.27\right)$. Nonparametric multiple comparisons using a Tukey-like test found a similar pattern to the number of individuals per person-hour rank means. Night VES and the leaf litter plots were significantly different from the DVES and opportunistic collecting at the 0.05 level, but not from each other. Day visual encounter surveys and 
Table 8. Comparison of the number of species caught per person hour during a sampling period among methods: opportunistic collecting (OC), leaf litter plots (LLP), night visual encounter survey (NVES), and day visual encounter survey (DVES). Using the Kruskal-Wallis test a significant difference was found among these methods at the 0.01 level. These methods were then compared using nonparametric multiple comparisons test for unequal sample sizes. Letters (in italics) indicate the methods that were significantly different from each other (0.05).

\begin{tabular}{lllll}
\hline Method & $\mathrm{N}$ & Mean & Sum rank & Mean rank \\
\hline LLP & 78 & 1.13 & 17865 & $229.04 a$ \\
NVES & 140 & 0.96 & 29031 & $207.36 a$ \\
DVES & 92 & 0.68 & 15309.5 & $166.41 b$ \\
OC & 54 & 0.34 & 4224.5 & $78.23 c$ \\
\hline
\end{tabular}


opportunistic collecting were significantly different from each other and all other methods. Night visual encounter surveys and leaf litter plots caught the largest number of species per person-hour. However, 203 out of 257 (79\%) leaf litter plots contained no animals. Opportunistic collecting caught the lowest number of species per unit of effort.

\section{Method biases}

Relative species richness percentages of different amphibian and reptilian families were calculated for each method and the combination of all methods to look for any biases. Seven families of reptile were collected by all methods. Leaf litter plots only captured three families and NVES captured all seven taxa (Figure 29). For amphibians, either opportunistic collecting or NVES had similar percentages to the percentages using all methods. Day visual encounter survey had a high percentage of bufonids while leaf litter plots had greater numbers of leptodactylids and bufonids (Figure 30). The different methods did not collect the same taxa. Some amphibian and reptilian families were not represented by the four methods (Table 9). Leaf litter plots are missing the largest number amphibian and reptilian families which are found in the Iwokrama Reserve. Opportunistic 


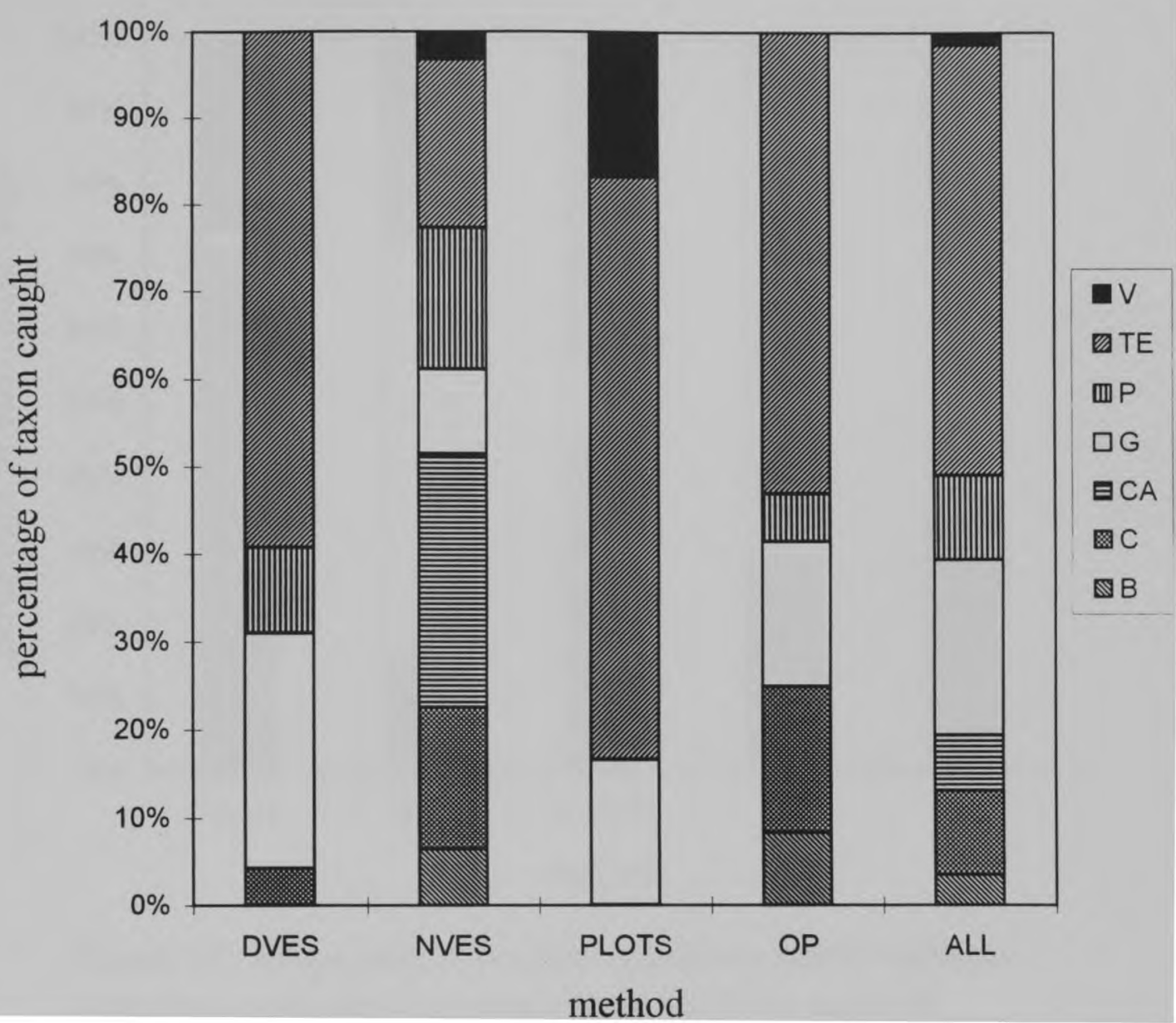

Figure 29. Percentage of relative family richness using four methods or a combination of all the methods.

Percentage of common reptilian families caught using four methods. $\mathrm{B}=$ Boidae, $\mathrm{C}=$ Colubridae, $\mathrm{CA}=$ Crocodilidae, $\mathrm{G}=$ Gekkonidae, $\mathrm{P}=$ Polychrotidae, $\mathrm{TE}=$ Teiidae, $\mathrm{V}=$ Viperidae Chelidae, Elapidae, Emydidae, Scinidae, Tropiduridae, Testudinidae and Typholopidae were caught but at levels less than $5 \%$. 


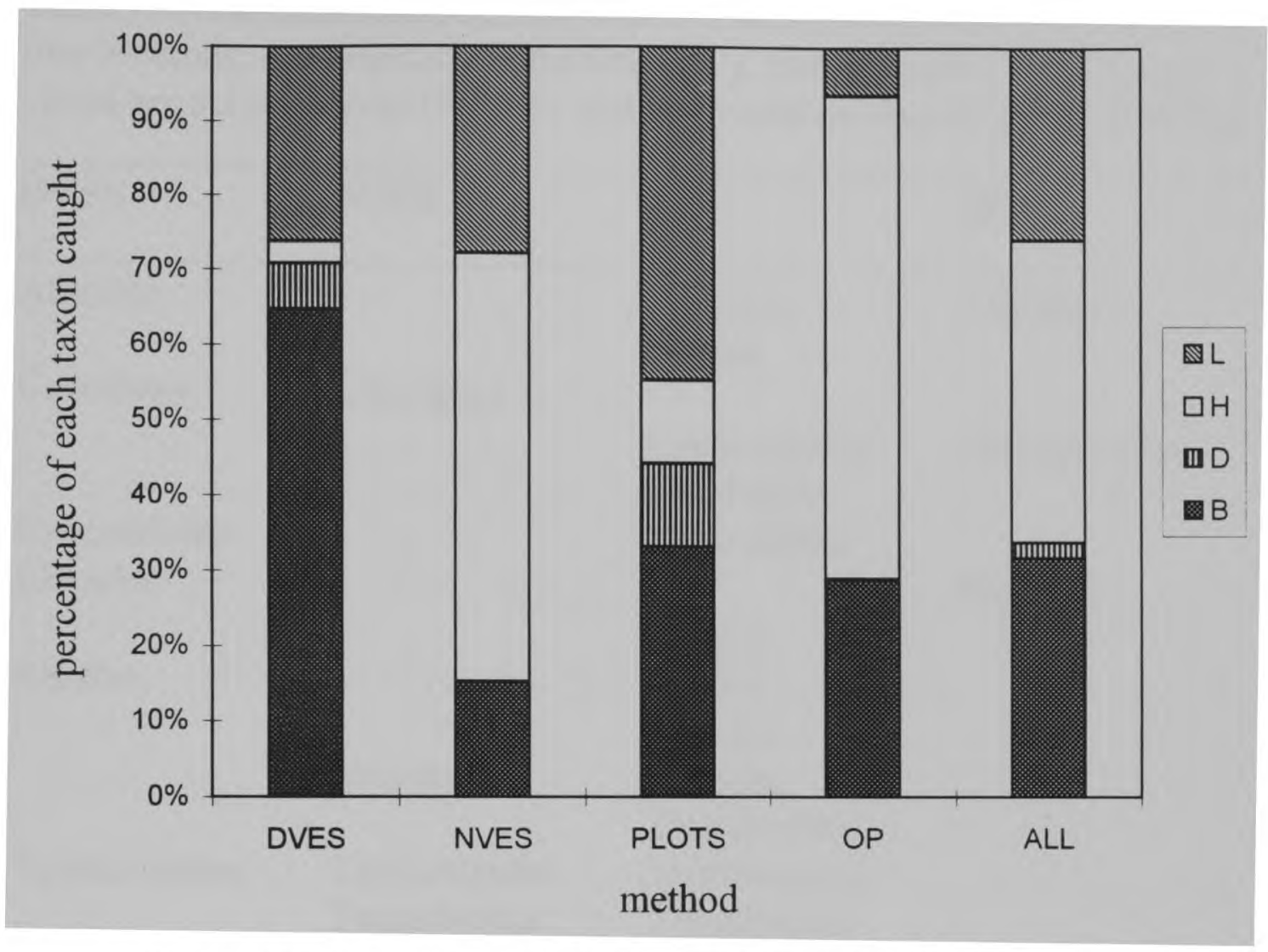

Figure 30. Proportion of relative amphibian family richness using four methods or a combination of all the methods.

Percentage of relative common amphibian family richness caught by different methods. B=Bufonidae, $\mathrm{D}=$ Dendrobatidae, $\mathrm{H}=$ Hylidae, $\mathrm{L}=$ Leptodactylidae.

Centrolenidae, Caecilians, Microhylidae, Ranidae, and Pipidae were caught but at levels less than $5 \%$. 
Table 9. Amphibian and reptilian families which were not collected by the four methods: opportunistic collecting (OC), leaf litter plots (LLP), night visual encounter survey (NVES), and day visual encounter survey (DVES).

\begin{tabular}{llll}
\hline DVES NVES & LLP & OC
\end{tabular}

\begin{tabular}{llll}
\hline Anilidae & & $\begin{array}{l}\text { Anilidae } \\
\text { Boidae }\end{array}$ & Anilidae \\
Caecilians & Caecilians & $\begin{array}{l}\text { Centrolenidae } \\
\text { Colubridae } \\
\text { Crocodilidae }\end{array}$ & Centrolenidae \\
Crocodilidae & & Elapidae \\
Elapidae & & $\begin{array}{l}\text { Hylidae } \\
\text { Pipidae }\end{array}$ & \\
Pipidae & & $\begin{array}{l}\text { Ranidae } \\
\text { Scinidae } \\
\text { Tropiduridae }\end{array}$ & \\
& Scinidae & $\begin{array}{l}\text { Typholopidae } \\
\text { Testudinidae } \\
\text { Chelidae }\end{array}$ & \\
Typholopidae & Typholopidae & \\
Chelidae & Testudinidae & & \\
Emydidae & & & \\
& & & \\
& & & \\
& & &
\end{tabular}


collecting was missing the smallest number of amphibian and reptilian families.

Species lists from each method and all combinations of methods were compared to the "best" estimate of species richness for the Iwokrama Reserve (Table 10). The combination of DVES, NVES, and opportunistic collecting caught the same number of species as the "best" estimate using all the data collected. The combination of NVES and opportunistic collecting caught the most species for any combination of two methods. Night visual encounter survey was the most successful as a single method. The leaf litter plots and pitfall traps caught no unique species. Leaf litter plots also caught the least number of species. A similar analysis was completed using genera and family richness. The ranking of the "best" methods was the same as the species richness analysis.

\section{$\underline{\text { Discussion }}$}

There are some standard amphibian and reptile sampling methods used in the field (Heyer et al. 1994). However, a quantitative examination of these different methods has not been done. This study examined the relative species richness and abundance collected by different inventory 
Table 10. Number of species collected using one method or a combination of methods: opportunistic collecting (OC), leaf litter plots (LLP), night visual encounter survey (NVES), and day visual encounter survey (DVES).

Method(s) Number of species collected $\%$ total

\begin{tabular}{lll}
\hline All methods & 98 & $100 \%$ \\
DVES, NVES, OC & 98 & $100 \%$ \\
NVES, OC & 86 & $87.8 \%$ \\
NVES, LLP, OC & 86 & $87.8 \%$ \\
DVES, NVES, LLP & 84 & $85.7 \%$ \\
DVES, NVES & 83 & $84.7 \%$ \\
DVES, OC & 81 & $82.7 \%$ \\
NVES, LLP & 69 & $70.4 \%$ \\
LLP, OC & 69 & $70.4 \%$ \\
NVES & 65 & $66.3 \%$ \\
OC & 64 & $65.3 \%$ \\
DVES, LLP & 49 & $50.0 \%$ \\
DVES & 45 & $45.9 \%$ \\
LLP & 15 & $15.3 \%$ \\
\end{tabular}


methods. Previous work by Pearman et al. (1995) suggested that different sampling methods will show differences in assemblage structure. In particular, Pearman et al. (1995) found that night visual encounter surveys provide the most accurate species richness for an area. However, the efficiency of different methods and the "best" combination of methods were not examined by this study. I compared four common amphibian and reptile sampling methods by looking at the differences in assemblage structure and number of animals caught per collection effort with different methods.

\section{Abotic factors}

I looked for patterns within these data controlled by external factors (e.g., rainfall and short-term temporal patterns). I did not find a relationship between rainfall and the number of individuals or the number of species. Nor was there a strong relationship between time and the number of individuals or number of species. These results allowed me to pool the data from all the sampling localities to examine patterns among the different localities and methods independent of environmental factors.

\section{Sampling time}

Species accumulation curves show the relationship between species richness and the number of individuals or length of sampling at a location. 
The point at which an asymptote is reached provides researchers with an understanding of how close they are to the actual species richness of the site (Rodriguez and Cadle 1990). Species accumulation curves for the Iwokrama Reserve showed a high level of species richness (Figure 7). Over 3,000 individuals were sampled in 68 days of collecting and the curve did not reach an asymptote at 98 species. These data suggest that the sampling time needs to be extended to portray an accurate picture of Iwokrama Reserve. The time of collecting was during the major wet season. Additional species could be found by sampling for a longer period of time or during another time of the year (Rodriguez and Cadle 1990). The most efficient way to describe the herpetofaunal assemblage would be to use many methods for as longest possible time period. The likelihood of encountering new species increases over a longer sampling period because animals with different spatial and temporal patterns can be observed. Rodriguez and Cadle (1990) developed comparable species accumulation curve of anurans species from Cocha Cashu, Manu National Park, Peru. After 115 days of field collecting, $85 \%$ of the known anuran species had been collected and their curve started to reach an asymptote. Such findings suggest that a period of time much longer than 68 days of sampling or the 
sampling of more individuals is needed to provide an accurate idea of the "true" species diversity within the Iwokrama Reserve.

Species accumulation curves were also calculated for each locality sampled (Figure 8 and 9). There was a similar pattern among localities compared to the species accumulation curve for the entire Iwokrama Reserve. My data concur with Hayek and Buzas (1997) who reported that most temperate localities sampled reach an asymptote between 200-500 individuals, but such asymptotes are not characteristic of tropical communities. Three of the camps (Three Mile, Burro-Burro, and Kabocalli) reached an asymptote between 500-600 individuals. While two of the three camps sampled for more than 10 days appeared to reach an asymptote, the third (Pakatau) did not. The other camps were not sampled long enough even though over 200 individuals were caught at seven of the eight camps. Each locality within the Iwokrama Reserve needed to be sampled longer than 11 days (the maximum length of stay at one camp).

\section{Differences among the camps}

All localities sampled were compared to find differences in species richness and evenness among the camps (Figure 10 and 11). The camps had similar log-log species accumulation patterns. The slopes of the equations 
differed suggesting that these camps support discrete communities which display unique patterns of species richness. The localities sampled were all lowland wet tropical forest, but they had different defining characteristics (e.g., in the vicinity of a river, elevation, or type of forest) which suggests these factors affect their species richness patterns. Species richness was significantly different among the eight camps sampled. Three of the camps, Pakatau, Kabocalli, and Burro-Burro, were located directly on major rivers (the Siparuni, Essequibo, and Burro-Burro Rivers respectively). Three other camps, Muri Scrub, Cutline A-B, and Three Mile, were located off the Georgetown-Lethem road. The final two camps, Cowfly and Third, were at a higher elevation, $120 \mathrm{~m}$ and $224 \mathrm{~m}$ respectively, in the foothills of the Iwokrama Mountain Range. These camp characteristics could have influenced the species accumulation and account for the differences in species richness estimates. Species evenness was shown to have a similar pattern among all eight camps (Figures 13 and 14). There were high numbers of rare species and low numbers of common species. Such findings suggest that these camps differ in their assemblage species richness, but not species evenness. 


\section{Standardized by the number of individuals}

The linear equations were used to estimate species richness among the methods. There were differences in species richness when the methods were standardized by the number of individuals. Opportunistic collecting had a different curve from the other methods at low numbers of individuals which is probably due to sampling error. Initially, people were inefficient at collecting species opportunistically but as time went on people would only collect animals if they were new species. This procedure caused the opportunistic collecting species richness estimate to be lower than the other methods because people were not consistent in their sampling. Day VES, NVES, and opportunistic collecting had different estimates of species richness at higher numbers of individuals suggesting that the three methods accumulate species at different rates. Although, these data were standardized by taking equal number of individuals the methods do not accumulate species at the same rate.

\section{Standardized by the number of person-hours}

Standardizing these data in a different way did not change the results. Night VES and opportunistic collecting had similar estimate at low numbers of person-hours. Day VES and leaf litter plots also had similar estimates of 
species richness at low number of person-hours. However, three methods differed in their species richness estimates at higher levels of effort (i.e., person-hours). The opportunistic collecting species richness per personhours was a conservative estimate because the actual time spent was unknown. Opportunistic collecting was completed while people were in camp and not easily accounted. It is a very efficient method of sampling that may vary significantly among observers and probably would have a higher species accumulation than the other methods because typically only new species were collected. Relative species abundances did not vary among methods when standardized using person-hours of effort. These data suggest that the methods have distinctly different patterns of species accumulation which lead to differences in their species richness. Relative species abundance did not seem to be affected by the method used to sample.

\section{Cluster analysis}

The dendrogram using all the data was compared to dendrograms calculated using a single sampling method. The dendrogram using all the data seemed to be the most accurate based on general habitat characteristics. Two out of the three river camps were grouped together and the two camps 
at higher elevation were grouped together. The camps located on the road are also placed together with Muri Scrub the camp farthest from separated out. These data suggest that the assemblage of the entire data set is correct. This pattern was not obtained by any one method.

\section{Method efficiency}

Nonparametric tests found that NVES caught significantly higher numbers of individuals and species per unit of effort. It was the most efficient in catching animals per unit of effort. The estimation of effort was very conservative, so this comparison is not as accurate as the other methods.

Leaf litter plots were also very successful in catching species per unit of effort, but $79 \%$ of the plots were void of animals making it a frustrating method to use at this site. Allmon (1994) and I found low leaf litter herpetofaunal abundances within Amazonia and Guyana, respectively which contrasts with the high abundances obtained from leaf litter plots in of Peru and Central America. Allmon (1994) suggests that central Amazonia and south-east Asia forests share a similar history of old deeply leeched soils that are poor in nutrients and low leaf litter herpetofaunal abundances. These characteristics sharply contrast with Central America and 
northwestern South America who have young volcanic soils that are high in nutrients. This suggests that the Amazonia region and Guyana lowland forests have low leaf litter herpetofaunal abundances that are linked to nutrient cycling and forest dynamics.

\section{Method biases}

One single method did not accurately describe the herpetofaunal assemblage. Some methods are biased toward certain families more than others. They had higher percentages of certain families then what is seen in the assemblage. Opportunistic collecting and DVES observed accurate percentages of the reptiles because many teiids are diurnal and other species are seen resting in the trees during the day. Opportunistic collecting and NVES had the most accurate percentages of amphibian families because a large proportion of the assemblage is most active at night. Opportunistic collecting and NVES observed the largest number of families which makes them more useful in general amphibian and reptile families. . These data suggest that opportunistic collecting, NVES, and DVES will provide researchers with the most accurate percentages of herpetofaunal families within the Iwokrama Reserve. 
One goal of this research was to determine which methods would yield the best information for the least amount of time and effort. The single best method was NVES which agrees with Pearman et al. (1995). The best estimate of species richness was produced using opportunistic collecting, DVES, and NVES. These three methods provided a species list identical to the list of all the species collected in the reserve. These data suggest that leaf litter plots did not need to be completed during this sampling period because they were not informative during the inventory sampling within the Iwokrama Reserve but they result in density estimates. Pitfall traps were only completed at one location, but they did not provide any new species to the richness of the reserve. The pitfall traps caught ground dwelling frog and lizard species, but not snakes. All other amphibian and reptilian species were probably able to escape the traps once they were caught. The pitfall traps should be run at additional locations before they are ruled out, but from a preliminary analysis they did not provide additional information for the Iwokrama Reserve.

\section{Conclusion}

In a time of dramatic species loss, collecting baseline data and being able to compare data among different studies is of the utmost importance for 
conservation. Studying herpetofaunal assemblages is especially important in understanding ecological dynamics during a time of unexplained recent amphibian declines. I researched the accuracy and efficiency in sampling methods by collecting basic community parameters such as species abundance and richness. These parameters are key to our understanding of community structure and ecosystem conservation.

In terms of the overall study, additional sampling needed to be completed to supply a more complete list of species for the entire Iwokrama Reserve. Ideally, each individual camp should have been sampled longer to give a more complete picture of the species diversity at each location and the differences among the camps. Increasing the length of sampling is in accordance with previous sampling completed in the Neotropics (Rodriguez and Cadle 1990; Hayek and Buzas 1997). The species diversity among camps varied in terms of species richness, but not relative species abundance patterns.

Estimations of species richness varied among methods even when these data were standardized using the number of individuals and or the number of person-hours expended. The study found that species richness estimates can be compared among sites using DVES, NVES, or leaf litter 
plots only if the same methods are used and the data is standardized. These findings caution researchers in comparing species diversity among studies because methods estimate species richness differently. No method supplied enough information to be used alone to describe the assemblage structure of Iwokrama Reserve. However, a combination of two or three methods provided more efficient and accurate baseline data for the Iwokrama Reserve. 


\section{LITERATURE CITED}

Allmon, W.D. 1994. A plot study of forest floor litter frogs, Central Amazon, Brazil. J. of Trop. Biol. 7:503-522.

Anonymous. 1996. Iwokrama international rain forest programme operational plan 1996-2000.

Balkuom, G.D., P.E. Hale, and A. Sydney Johnson. 1996. Relative effectiveness of three types of small mammal traps. Fl. Sci. 59(2):118-120.

Baltanau, A. 1992. On the use of some methods for the estimation of species-richness. Oikos 65:484-492.

Blaustein, A.R., and D.B. Wake, and N.P. Sousa. 1994. Amphibian declines: judging stability, persistence, and susceptibility of population to local and global extinctions. Conserv. Biol. 8(1):60-71.

Blaustein, A.R., and D.B. Wake. 1990. Declining amphibian population: a global phenomenon? Trends in Ecol. and Evol. 5(7):203-204.

Burton, T.M., and G.E. Likens. 1975. Salamander populations and biomass in the Hubbard Brooks Experimental forest, New Hampshire. Copeia 1975 (3):541-546.

Busby, W.H., and J.R. Parmalee. 1996. Historical changes in a herpetofaunal assemblage in the flint hills of Kansas. Am. Mid. Nat. 135:81-91.

Condit, R., S.P. Hubbell, J.V. Lafrankie, R. Sukumar, N. Manokaran, R.B. Foster, and P.S. Ashton. 1996. Species-area and species-individual relationships for tropical trees: a comparison of three 50 -ha plots. $J$. of Ecology 84: 549-562.

Corn, P.S. 1994. Straight-line drift fences and pitfall traps In Measuring and monitoring biological diversity. Standard methods for amphibians. W.R. Heyer, M.A. Donnelly, R.W. McDiarnid, L.C. 
Hayek, and M.S. Foster (eds.) pages 109-117. Smithsonian Institution Press, Washington D.C.

Crump M.L., and N.J. Scott Jr. 1994. Visual encounter surveys In Measuring and monitoring biological diversity. Standard methods for amphibians. W.R. Heyer, M.A. Donnelly, R.W. McDiarnid, L.C. Hayek, and M.S. Foster (eds.) pages 84-92. Smithsonian Institution Press, Washington D.C.

Donnelly, M.A., and M.L. Crump. In press. Potential effects of climate change on two neotropical amphibian assemblages. Climatic Change

Duellman, W. 1995. Temporal fluctuations in abundances of anuran amphibians in a seasonal Amazonian rainforest. J. of Herp. 29(1): 13-21.

Friend, G.R., and K.M. Cellier. 1990. Wetland herpetofauna of Kakadu National Park, Australia: seasonal richness trends, habitat preferences and the effects of feral ungulates. J. of Trop. Ecol. 6:131-152.

Gaston, K.J. 1996. Community composition and nested-subset analysis basic descriptors for community ecology. Oikos 76:417-426.

Gotelli, N.J., and G.R. Graves. 1996. Null models in ecology. Smithsonian Inst. Press. Washington D.C.

Greenberg, C.H., and D.G. Neary, and L.D. Harris. 1994. A comparison of herpetofaunal sampling effectiveness of pitfall, single-ended, and double-ended funnel traps used with drift fences. J. of Herp. 28(3):319-324.

Hawkes, M.D., and J.R.D. Wall. 1995. The commonwealth and government of Guyana Iwokrama rain forest programme. Phase 1. Camp resource survey. Main report. Natural Resources Institute. Hobbs, Southampton, England.

Hayek, L.C., and M.A. Buzas. 1997. Surveying natural populations. Columbia Unviersity Press. New York, N.Y. 
Heatwole, H.F., and J. Taylor. 1987. Ecology of Reptiles. Surrey Beatty \& Sons Pty Limited. Chipping Norton, NSW, Australia.

Hecnar, S.J., and R.T. M'Closkey. 1996. Regional dynamics and the status of amphibians. Ecology 77(7):2091-2097.

Hecnar, S.J., and R.T. M'Closkey. 1997. Changes in the composition of a ranid frog community following bullfrog extinction. Am. Mid. Nat. 137:145-150.

Heinen, J.T. 1992. Comparisons of the leaf litter herpetofauna in abandoned cacao plantations and primary rain forest in Costa Rica: some implications for faunal restoration. Biotropica 24(3):431-439.

Henke, S.E. 1998. The effect of multiple search items and item abundance on the efficiency of human searchers. J. of Herpetology 32(1):112115

Heyer W.R., W.R., M.A. Donnelly, R.W. McDiarnid, L.C. Hayek, and M.S. Foster. 1994. Measuring and monitoring biological diversity. Standard methods for amphibians. Smithsonian Institution Press, Washington, D.C.

Inger, R.F. 1980. Relative abundances of frogs and lizards in forests of southeast Asia. Biotropica 12(1):14-22.

Inger, R.F., H.B. Shaffer, M. Koshy, and R. Bakde. 1987. Ecological structure of a herpetological assemblage in south India. AmphibiaReptilia 8:189-202.

Inger, R.F., and R.K. Colwell. 1977. Organization of contiguous communities of amphibians and reptiles in Thailand. Ecol. Mono. 47:229-253.

Jaeger, R.G., and R.F. Inger. 1994. Quadrat sampling In Measuring and monitoring biological diversity. Standard methods for amphibians. W.R. Heyer, M.A. Donnelly, R.W. McDiarnid, L.C. Hayek, and M.S. Foster (eds.) pages 97-102. Smithsonian Institution Press, Washington D.C. 
Kerr, B. 1993. Iwokrama: the commonwealth rain forest programme in

Guyana. Commonwealth Forest Review 72(4): 305-309.

Lieberman, S.S. 1986. Ecology of the leaf litter herpetofauna of neotropical rain forest: La Selva, Costa Rica. Acta zoologica mexicana no. 15, Instituto de Ecologia, D.F. Mexico. 72 pages.

Losos, J.B. 1994. Historical contingency and lizard community ecology in Lizard ecology: historical and experimental perspectives LJ. Vitt and E.R. Pianka (eds.) pages 319-333.

Magurran, A.E. 1988. Ecological diversity and its measurement. Princeton University Press. Princeton, N.J.

McCarthy, M.A., D.B. Lindenmayer, and M.Drechsler. 1997. Extinction debt and risks faced by abundant species. Cons. Biol. 11(1):221-226.

Merriam-Webster, Incorporated. 1995. Merriam-Webster's collegiate dictionary Tenth edition. Springfield, MA.

Miller, R.I., and P.S. White 1986. Considerations for preserve design based on the distribution of rare plants in Great Smoky Mountains National Park, U.S.A. Environmental Management 10(1):119-124.

Moreira, G., and A.P. Lima. 1991. Seasonal patterns of juvenile recruitment and reproduction in four species of leaf litter frogs in central Amazonia. Herpetologica 47(3): 295-300.

Nilsson, C. and G. Grelsson. 1995. The fragility of ecosystems: a review. J of Applied Ecol. 32:677-692.

Pearman, P.B., A.M. Velasco, and A. Lopez. 1995. Tropical amphibian monitoring: a comparison of methods for detecting inter-site variation in species composition. Herpetologica 51(3):325-337.

Ricklefs,R.E. 1990. Ecology. W.H. Freeman and Company. New York, N.Y. 
Rodriguez, L.B., and J.E. Cadle. 1990. A preliminary overview of the herpetofanua of Cocha Cashu, Manu National Park, Peru In Four Neotropical rainforests. A.H. Gentry (ed.) pages 410-425 Yale University Press, New Haven, CT.

Scott, N.J. Jr. 1994. Complete species inventories In Measuring and monitoring biological diversity. Standard methods for amphibians. W.R. Heyer, M.A. Donnelly, R.W. McDiarnid, L.C. Hayek, and M.S. Foster (eds.) pages 78-84. Smithsonian Institution Press, Washington D.C.

Scott, N.J. Jr. 1976. The abundance and diversity of the herpetofaunas of tropical forest litter. Biotropica 8(1): 41-58.

Scott, N.J., Jr., and Campbell, H.W., 1982. A chronological bibliography, the history, and status of studies of herpetological communities, and suggestions for future research. Herpetological communities U.S. Dept. of the Interior Fish and Wildlife Service wildlife research report. 13:221-239.

Statistica (for windows). Version 5.1. 1997. StatSoft, Inc. Tulsa, OK.

Steele, B.B., R.L. Bayn, Jr., and C.V. Grant. 1984. Environmental monitoring using population of birds and small mammals analyses of sampling effort. Biol. Cons. 30:157-172.

TableCurve $^{\mathrm{TM}}$ 2D. 1989-1994. Jandel Scientific AISN software.

Toft, C.A. 1980. Feeding ecology of thirteen syntopic species of anurans in a seasonal tropical environment. Oecologia 45: 131-141.

Tokeshi, M. 1993. Species abundance patterns and community structure. Advances in Ecological Research 24:111-186.

Turner, I.M. 1996. Species loss in fragments of tropical rain forest: a review of the evidence. J. of Applied Ecol. 33(2):200-209.

Vieira, V.S. 1980. Logging in Guyana and considerations for improvements. Guyana National Printers, Ltd., Guyana. 
Vitt, L.J., and J.P. Caldwell. 1994. Resource utilization and guild structure of small vertebrates in the Amazon forest leaf litter. J. of Zool. Lond. 234:463-476.

Williams, D.F., and S.E. Brown. 1983. Comparison of pitfall conventional traps for sampling small mammal populations. J of Wild. Manage. 47(3):841-845.

Williams, S.E., and R.E. Pearson . 1997. Historical rain forest contractions, extinctions, and patterns of vertebrate endemism in the rain forest of Australia's wet tropics. Proc. R. Soc. Lond. B 264(1382):709-716.

Worthen, W.B. 1996. Community composition and nested-subset analysis basic descriptors for community ecology. Oikos 76:417-426.

Zar, J.H. 1984. Biostatistical Analysis $2^{\text {nd }}$ edition. Prentice Hall Englewood Cliffs, NJ

Zimmerman, B.L., and D. Simberloff. 1996. An historical interpretation of habitat use by frogs in a central Amazonian forest. $J$. of Biogeography 23: 27-66. 